\title{
Olefin Metathesis in Continuous Flow Reactor Employing Polar Ruthenium Catalyst and Soluble Metal Scavenger for Instant Purification of Products of Pharmaceutical Interest
}

Ren Wei Toh, ${ }^{a, \ddagger}$ Michał Patrzałek,, , $\ddagger$ Tomasz Nienałtowski,,${ }^{b}$ Jakub Piątkowski, ${ }^{b}$ Anna Kajetanowicz,,${ }^{*}$ Jie $W u, a,{ }^{*}$ Karol Grela ${ }^{b,{ }^{*}}$

${ }^{a}$ Department of Chemistry, National University of Singapore, 3 Science Drive 3, Singapore 117543, Singapore

${ }^{\mathrm{b} B i o l o g i c a l}$ and Chemical Research Centre, Faculty of Chemistry, University of Warsaw, Żwirki i Wigury 101, 02-089 Warsaw, Poland

'Pharmaceutical Works Polpharma SA, Pelplińska 19, 83-200 Starogard Gdański, Poland

E-mails of corresponding authors:

prof.grela@gmail.com (K. Grela);

chmjie@u.nus.edu (J.Wu);

a.kajetanowicz@uw.edu.pl (A. Kajetanowicz)

Number of pages: 24

Number of tables: 1

Number of figures: 23

Number of schemes: 4 


\section{Table of Contents}

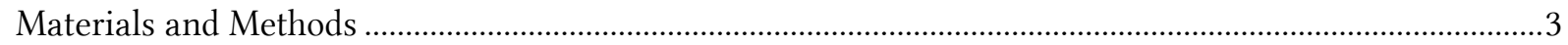

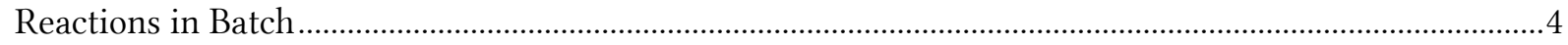

General Procedure for RCM (Ring Closing Metathesis) Reactions in Batch..............................................4

Procedure for RCM Reaction of Pacritinib Precursor in Batch ......................................................................6

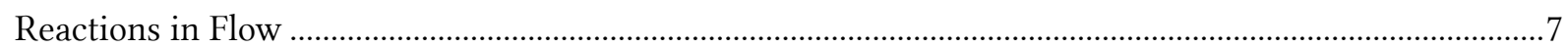

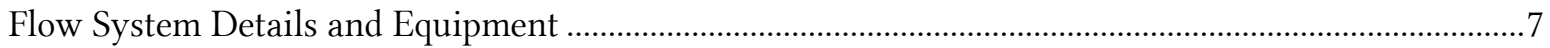

General Procedure for RCM (Ring Closing Metathesis) Reactions in Flow in Small Scale......................8

Procedure for RCM Reaction of Sildenafil Derivative in Flow in Larger Scale ........................................10

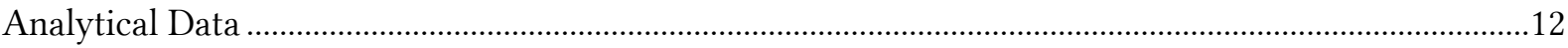

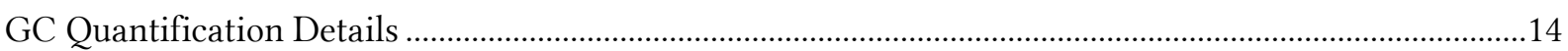

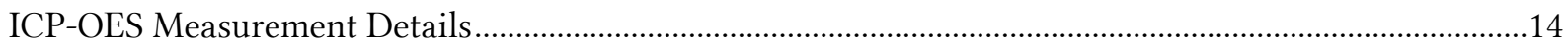

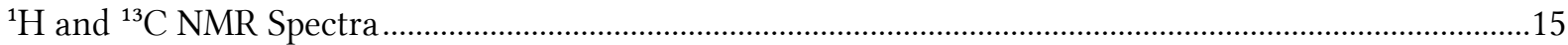

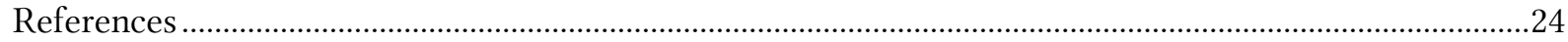




\section{Materials and Methods}

General Remarks: unless otherwise noted, all materials were purchased from commercial suppliers and used as received. All reactions requiring exclusion of oxygen and moisture were carried out in oven-dried glassware with dry solvents (purified using MBraun SPS) under a dry and oxygen-free atmosphere using Schlenk technique. The bottles with ruthenium catalysts were stored under argon atmosphere, but no special precautions were taken to avoid air or moisture exposure in the moment of extracting the catalysts from the bottles.

Analytical Reagent (AR) Grade Ethyl Acetate (EtOAc) or Dichloromethane (DCM) was used for the batch and flow reactions. The solvent was dried over $4 \AA$ molecular sieves (dried in the oven at $100{ }^{\circ} \mathrm{C}$ overnight) and bubbled with argon gas for at least 15 minutes.

Nuclear Magnetic Resonance (NMR): NMR $\left({ }^{1} \mathrm{H}\right.$ and $\left.{ }^{13} \mathrm{C}\right)$ spectra were recorded on Agilent Mercury $400 \mathrm{MHz}$, Bruker AV-III400 $400 \mathrm{MHz}$, or AMX500 $500 \mathrm{MHz}$ spectrometers at ambient temperature with $\mathrm{CDCl}_{3}$ and $\mathrm{CD}_{2} \mathrm{Cl}_{2}$ used as a solvent purchased from Sigma-Aldrich or Eurisotop which was stored over molecular sieves and silver foil. Chemical shifts $(\delta)$ are given in parts per million (ppm) downfield from tetramethylsilane with a residual protio solvent signal used as a reference: $\mathrm{CDCl}_{3}\left(\delta_{\mathrm{H}}=7.26 \mathrm{ppm}, \delta_{\mathrm{C}}=77.16 \mathrm{ppm}\right), \mathrm{CD}_{2} \mathrm{Cl}_{2}\left(\delta_{\mathrm{H}}=5.32 \mathrm{ppm}, \delta_{\mathrm{C}}=54.00\right.$ ppm). Coupling constants $(J)$ are reported in hertz $(\mathrm{Hz})$ and refer to $\mathrm{H}, \mathrm{H}$-coupling. The following abbreviations are used in order to indicate the multiplicity of the signal: s (singlet), d (doublet), $\mathrm{t}$ (triplet), q (quartet), quin (quintet), sext (sextet), hept (heptet), dd (doublet of doublet), dt (doublet of triplet), ddd (doublet of doublet of doublet) etc., bs (broad signal), m (multiplet). The obtained data was processed using MestReNova software.

Gas Chromatography (GC): GC measurements conducted at the Biological and Chemical Research Centre were carried out using PerkinElmer Clarus 580 with FID detector employing InertCap 5MS-Sil Capillary Column (inner diameter $0.25 \mathrm{~mm}$, length $30 \mathrm{~m}$, df $0.50 \mu \mathrm{m}$ ) and helium as a carrier gas. Analyses performed at the National University of Singapore (under the supervision of Associate Professor Ge Shaozhong) were carried out using Shimadzu GC$2030 A F-1095$.

Column Chromatography (CC): CC was performed using Merck Millipore silica gel (60, particle size $0.043-0.063 \mathrm{~nm})$ or SANPONT silica gel $60(63-200 \mu \mathrm{m})$ with EtOAc/n-hexane system as eluent, unless otherwise stated.

Thin Layer Chromatography (TLC): TLC was performed using Merck Silica Gel $60 \mathrm{~F}_{254}$ precoated aluminum sheets $(0.25 \mathrm{~mm}$ thickness). Substances were visualized using UV-light (254 or $365 \mathrm{~nm}$ ) or by stains: $\mathrm{KMnO}_{4} / \mathrm{K}_{2} \mathrm{CO}_{3} / \mathrm{NaOH}$ (aqueous solution) or anisaldehyde $/ \mathrm{H}_{2} \mathrm{SO}_{4}$ (ethanolic solution).

Inductively Coupled Plasma Optical Emission Spectrometry (ICP-OES): ICP-OES results were obtained at EA analytical laboratory at the National University of Singapore using Perkin Elmer Avio 500 spectrometer. 


\section{Reactions in Batch}

\section{General Procedure for RCM (Ring Closing Metathesis) Reactions in Batch}

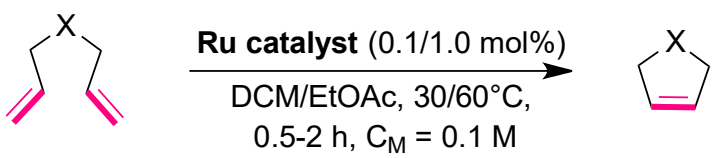

Scheme S1. General scheme for RCM reactions in batch.

Reactions were performed in dry solvents (DCM or EtOAc) under argon atmosphere. Stock solution of catalyst was prepared by dissolving $0.02 \mathrm{mmol}$ of the appropriate catalyst $(\mathrm{Ru} 1 \mathrm{or}$ $\mathrm{Ru} 2)$ in $1 \mathrm{~mL}$ of DCM or EtOAc $\left(\mathrm{C}_{\mathrm{M}}=0.02 \mathrm{M}\right)$. 0.1 M substrate solution $(3 \mathrm{~mL}, 0.3 \mathrm{mmol}, 1$ equiv.) was placed in an oven-dried vial followed by the addition of $0.02 \mathrm{M}$ solution of the catalyst $(15 / 150 \mu \mathrm{L}, 0.0003 / 0.0030 \mathrm{mmol}, 0.1 / 1.0 \mathrm{~mol} \%)$. The reaction mixture was stirred at the given temperature $\left(30 / 60{ }^{\circ} \mathrm{C}\right)$ and then, the solution of SnatchCat $(0.045 \mathrm{M}$ in DCM $)$ was added $(0.44 / 4.4 \mathrm{~mol} \%$ respectively for $0.1 / 1.0 \mathrm{~mol} \%$ of the ruthenium catalyst). The resulting mixture was stirred for 30-120 min (200 rpm). The product was purified using column chromatography (stationary phase: $\mathrm{SiO}_{2}$, eluent: reaction solvent). Yields for all substrates but 15 were calculated based on GC results using durene (1,2,4,5-tetramethylbenzene) as an internal standard or NMR experiments (for substrate 15).

Note: Compound 16 precipitated from the reaction mixture as colorless crystals when the reaction is carried out in EtOAc.

Table S1. Results of RCM reaction performed in batch.

\begin{tabular}{|c|c|c|c|c|c|c|}
\hline Substrate & Catalyst & Solvent & $\begin{array}{c}\text { Loading } \\
\text { [mol\%] }\end{array}$ & Product & $\begin{array}{c}\text { Yield [\%] } \\
\left(30^{\circ} \mathrm{C}\right)\end{array}$ & $\begin{array}{c}\text { Yield [\%] } \\
\left(60^{\circ} \mathrm{C}\right)\end{array}$ \\
\hline \multirow{8}{*}{$\mathrm{CtO}^{\mathrm{EtO}_{2} \mathrm{C}} \mathrm{CO}^{\mathrm{CO}_{2} \mathrm{Et}}$} & \multirow{4}{*}{$\mathrm{Ru} 1$} & \multirow{2}{*}{ DCM } & 1.0 & \multirow{8}{*}{$\mathrm{tO}_{2} \mathrm{C}>^{\mathrm{CO}}$} & 99 & - \\
\hline & & & 0.1 & & 83 & - \\
\hline & & \multirow{2}{*}{ EtOAc } & 1.0 & & 94 & 99 \\
\hline & & & 0.1 & & 30 & 31 \\
\hline & \multirow{4}{*}{$\mathrm{Ru} 2$} & \multirow{2}{*}{ DCM } & 1.0 & & 99 & - \\
\hline & & & 0.1 & & 81 & - \\
\hline & & \multirow{2}{*}{$\mathrm{EtOAc}$} & 1.0 & & 96 & 99 \\
\hline & & & 0.1 & & 33 & 33 \\
\hline \multirow{8}{*}{$\underbrace{\substack{1 \\
N}}_{3}$} & \multirow{4}{*}{ Ru1 } & \multirow{2}{*}{ DCM } & 1.0 & \multirow{8}{*}{$\mathrm{Cbz}$} & 99 & - \\
\hline & & & 0.1 & & 99 & - \\
\hline & & \multirow{2}{*}{ EtOAc } & 1.0 & & 99 & 99 \\
\hline & & & 0.1 & & 99 & 99 \\
\hline & \multirow{4}{*}{$\mathrm{Ru} 2$} & \multirow{2}{*}{ DCM } & 1.0 & & 99 & - \\
\hline & & & 0.1 & & 99 & - \\
\hline & & \multirow{2}{*}{ EtOAc } & 1.0 & & 99 & 99 \\
\hline & & & 0.1 & & 99 & 99 \\
\hline \multirow{4}{*}{${ }_{\pi}{ }^{P h}$} & \multirow{4}{*}{ Ru1 } & \multirow{2}{*}{$\mathrm{DCM}$} & 1.0 & & 99 & - \\
\hline & & & 0.1 & & 7 & - \\
\hline & & \multirow{2}{*}{ EtOAc } & 1.0 & & 94 & 99 \\
\hline & & & 0.1 & & 30 & 31 \\
\hline
\end{tabular}




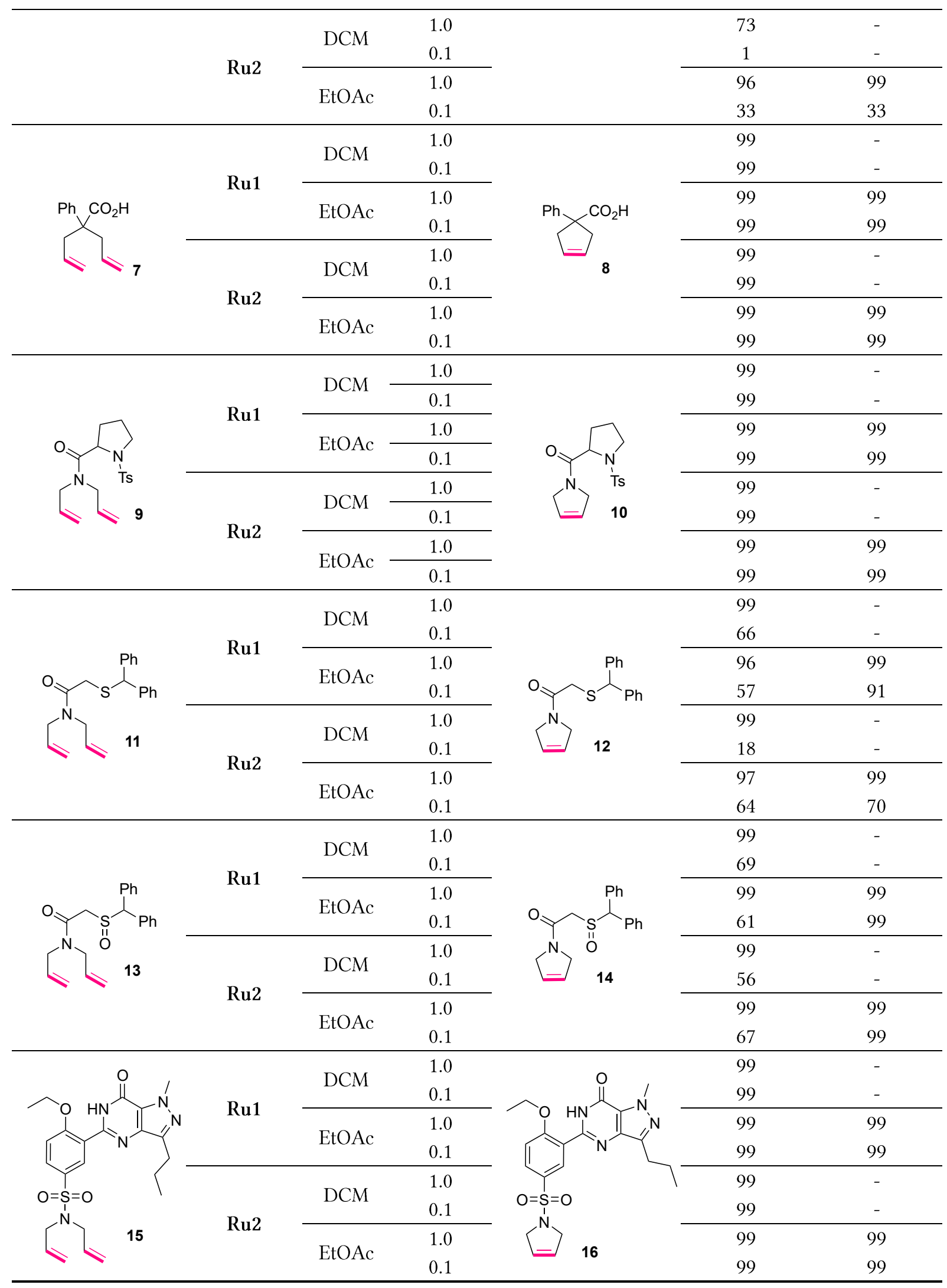

Conditions: substrate concentration - $0.1 \mathrm{M}$; reaction time for: EtOAc ( $1 \mathrm{~mol} \%$ of catalyst) - $30 \mathrm{~min}$, DCM (1 mol\% of catalyst) - $60 \mathrm{~min}, \mathrm{EtOAc} / \mathrm{DCM}$ (0.1 mol\% of catalyst) - $120 \mathrm{~min}$. Yields (1, 3, 5, 7, 9, 11, and 13) were calculated using GC with 1,2,4,5-tetramethylbenzene (durene) as internal standard or ${ }^{1} \mathrm{H}$ NMR in case of 15. 


\section{Procedure for RCM Reaction of Pacritinib Precursor in Batch}<smiles>C=CCOCc1cccc(-c2ccnc(Nc3ccc(OCCCl)c(COCC=C)c3)n2)c1</smiles>

17

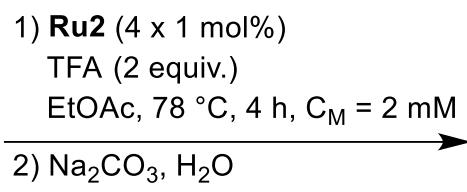

1) Ru2 ( $4 \times 1 \mathrm{~mol} \%)$ TFA (2 equiv.)

Scheme S2. Scheme of RCM reaction of Pacritinib precursor in batch.<smiles>ClCCOc1ccc(Nc2nccc(-c3cccc(COCC=CCOCCOCc4ccccc4)c3)n2)cc1</smiles>

18

Two-necked round-bottom flask was charged with $50 \mathrm{~mL}$ of EtOAc. Then, the precursor of Pacritinib 17 (50 mg, $0.1 \mathrm{mmol}, 1$ equiv.) was added $\left(\mathrm{C}_{\mathrm{M}}=2 \mathrm{mM}\right)$. Afterwards, trifluoroacetic acid (24.7 mg, $0.2 \mathrm{mmol}, 2$ equiv.) and $0.1 \mathrm{~mL}$ of Ru2 solution in DCM ( $9 \mathrm{mg}$ in $1 \mathrm{~mL}$ ) were added to the reaction mixture $(0.9 \mathrm{mg}, 0.001 \mathrm{mmol}, 1 \mathrm{~mol} \%)$. The reaction was carried out at $78{ }^{\circ} \mathrm{C}$. After each hour, next portion of the catalyst was added ( $1 \mathrm{~mol} \%$ ). A total of $4 \mathrm{~mol} \%$ of the catalyst (4 portions - $0.1 \mathrm{~mL}$ each) was added. Next, SnatchCat (0.0176 mmol, $17.6 \mathrm{~mol} \%$ vs substrate, 4.4 equiv. vs the catalyst) solution was added, solvents were evaporated and EtOAc/ $\mathrm{Na}_{2} \mathrm{CO}_{3}$ extraction was performed $(3 \times 30 \mathrm{~mL})$. Then, the crude product, after drying over $\mathrm{Na}_{2} \mathrm{SO}_{4}$, was purified using column chromatography (stationary phase: $\mathrm{SiO}_{2}$, eluent: EtOAc/n-hexane 15:85 to $20: 80 \mathrm{v} / \mathrm{v})$ to obtain $45.5 \mathrm{mg}(97 \%)$ of the product $18(E / Z=70: 30)$. The product forms yellow feathers.

Notes:

- after basic extraction the product does not contain TFA anion - it appears as free amine form (based on ${ }^{19} \mathrm{~F}$ NMR)

- $\quad E / Z$ ratio was found by calculations based on NMR signals. Two appropriate signals (one from $E$-isomer and second from $Z$-isomer) were found and integrated $(7.81 \mathrm{ppm}-E$ form, $7.76 \mathrm{ppm}-Z$-form). The integral sum was set at the value of 100 . 


\section{Reactions in Flow}

\section{Flow System Details and Equipment}

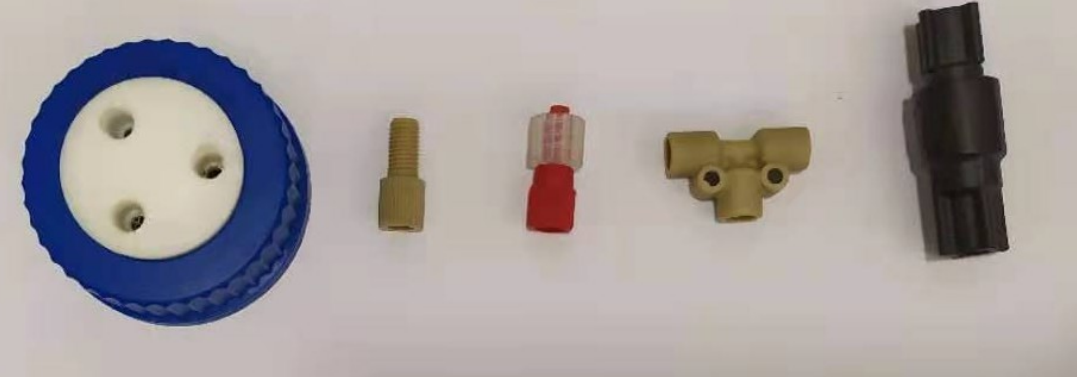

Figure S1. Flow system parts. From left to right: custom-made blue caps; 1/8 or 1/16 HPFA nut part; needle connector used for extracting reaction mixture into KDS stainless steel syringe; T-connector; back pressure regulator, 40 psi. Except for the blue caps, the remaining items can be purchased from IDEX Health \& Science LLC.

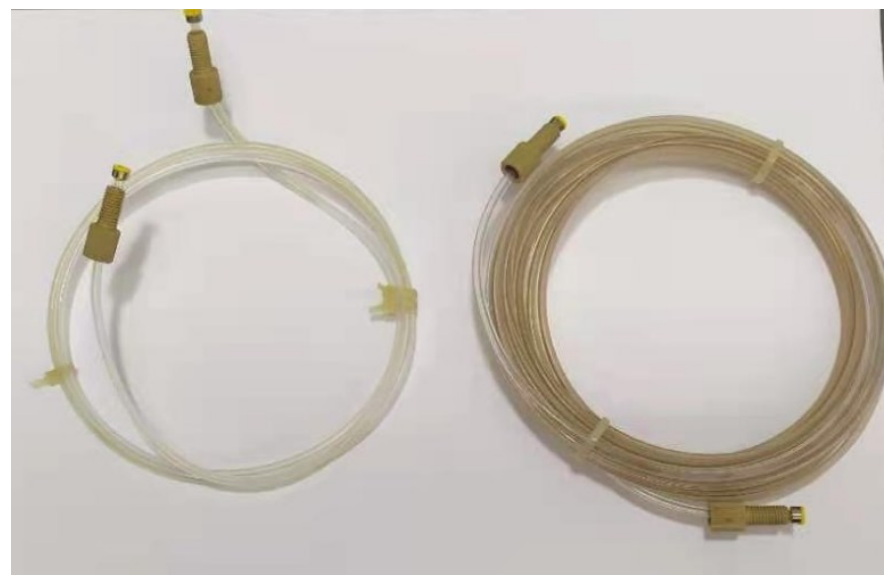

Figure S2. HPFA tubing. Details: 1/8, O.D. 1/16", I.D. 0.062"; left, small scale reaction, $2 \mathrm{~mL}$; right, large scale reaction, $10 \mathrm{~mL}$ ). Items can be purchased from IDEX Health \& Science LLC.

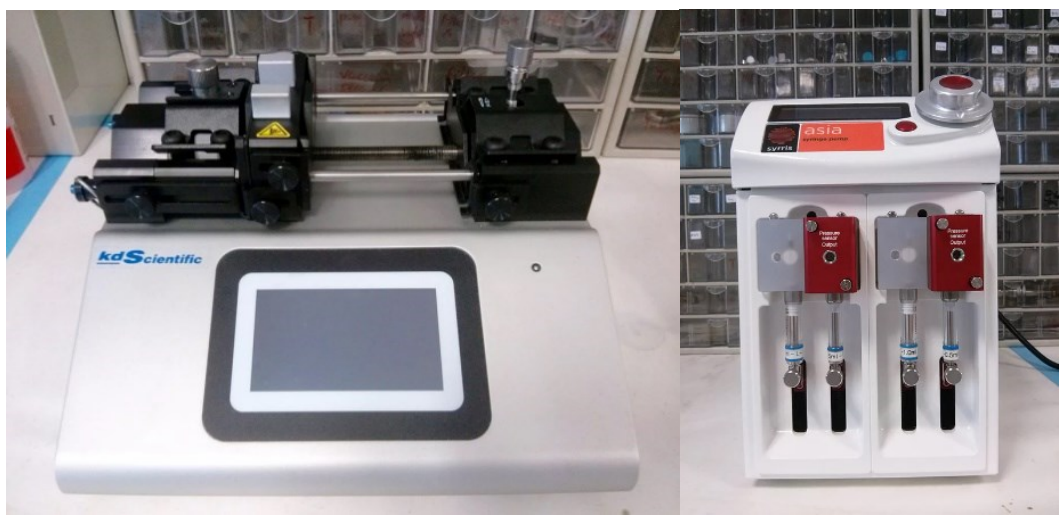

Figure S3. Pumps used along with flow set-up. The left one for small scale reactions (KDS syringe pump) and the right one for large scale reactions (Asia pump). 


\section{General Procedure for RCM (Ring Closing Metathesis) Reactions in Flow in Small Scale}

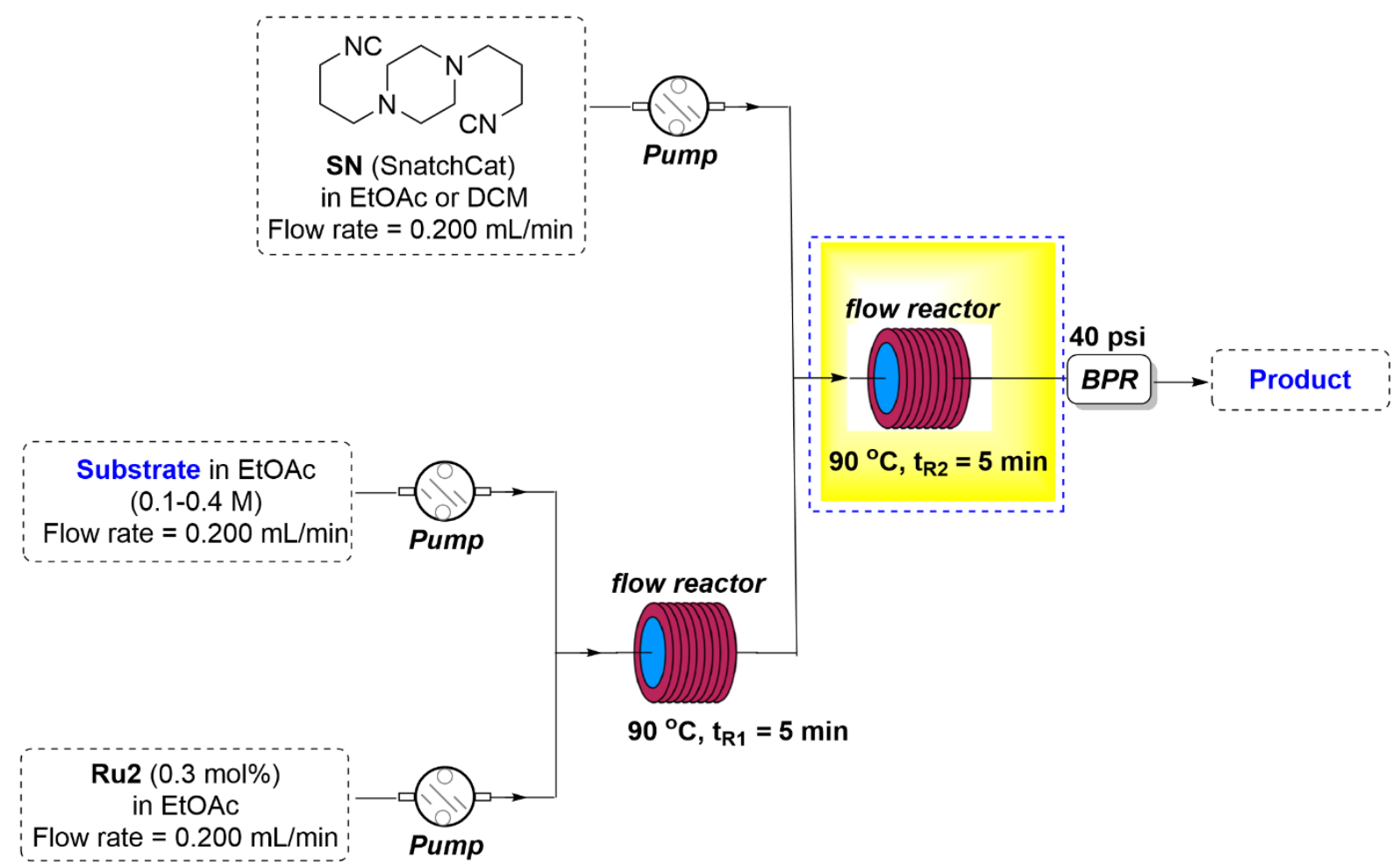

Scheme S3. General flow set-up diagram for testing substrates in small scale with varying concentration of the substrates depending on the solubility.

Substrate (2.4 mmol, 1 equiv.) and the catalyst Ru2 (6.1 mg, $0.0072 \mathrm{mmol}, 0.3 \mathrm{~mol} \%)$ were weighed separately, put into two different $20 \mathrm{~mL}$ vials (preheated in the oven for at least $30 \mathrm{~min}$ ), and covered with rubber septum caps tightly. Atmosphere exchange was done employing argon (as an inert gas) using vacuum pumps (three cycles were performed before attaching balloons filled with argon to each of the vials). Then, $8 \mathrm{~mL}$ of dried and argon-bubbled EtOAc was transferred into the vials via a disposable syringe and sonication was done to ensure that all the catalyst and substrate were fully dissolved. The final concentration before mixing in the $\mathrm{T}$-connector for the substrate was $0.4 \mathrm{M}$. Concentration of the substrates were varied based on the solubility in EtOAc.

Using an $8 \mathrm{~mL}$ KDS stainless syringe attached with a needle connector (Figure S1), the substrate solution was extracted from the $20 \mathrm{~mL}$ vial and connected to a KDS syringe pump. Another 8 $\mathrm{mL}$ KDS stainless syringe was filled with the Ru2 solution mixture and attached to the same KDS syringe pump. Meanwhile, SnatchCat scavenger (6.1 mg, $0.030 \mathrm{mmol}, 1.32 \mathrm{~mol} \%$, 4.4 equiv. $v s$ the catalyst) was dissolved in $5 \mathrm{~mL}$ of EtOAc and transferred into an $8 \mathrm{~mL}$ KDS stainless syringe. Likewise, the syringe was attached to a KDS syringe pump. The flow set-up is as shown in Scheme S3 with the tubing soaked in an oil bath (Figure S4) to provide heating for the reaction. After 2 residence timing $\left(t_{R}\right)$ of 20 minutes, the product was collected at the end of the silica packed-bed and concentrated under vacuum before further analysis using GC, NMR or ICP-MS were performed. 


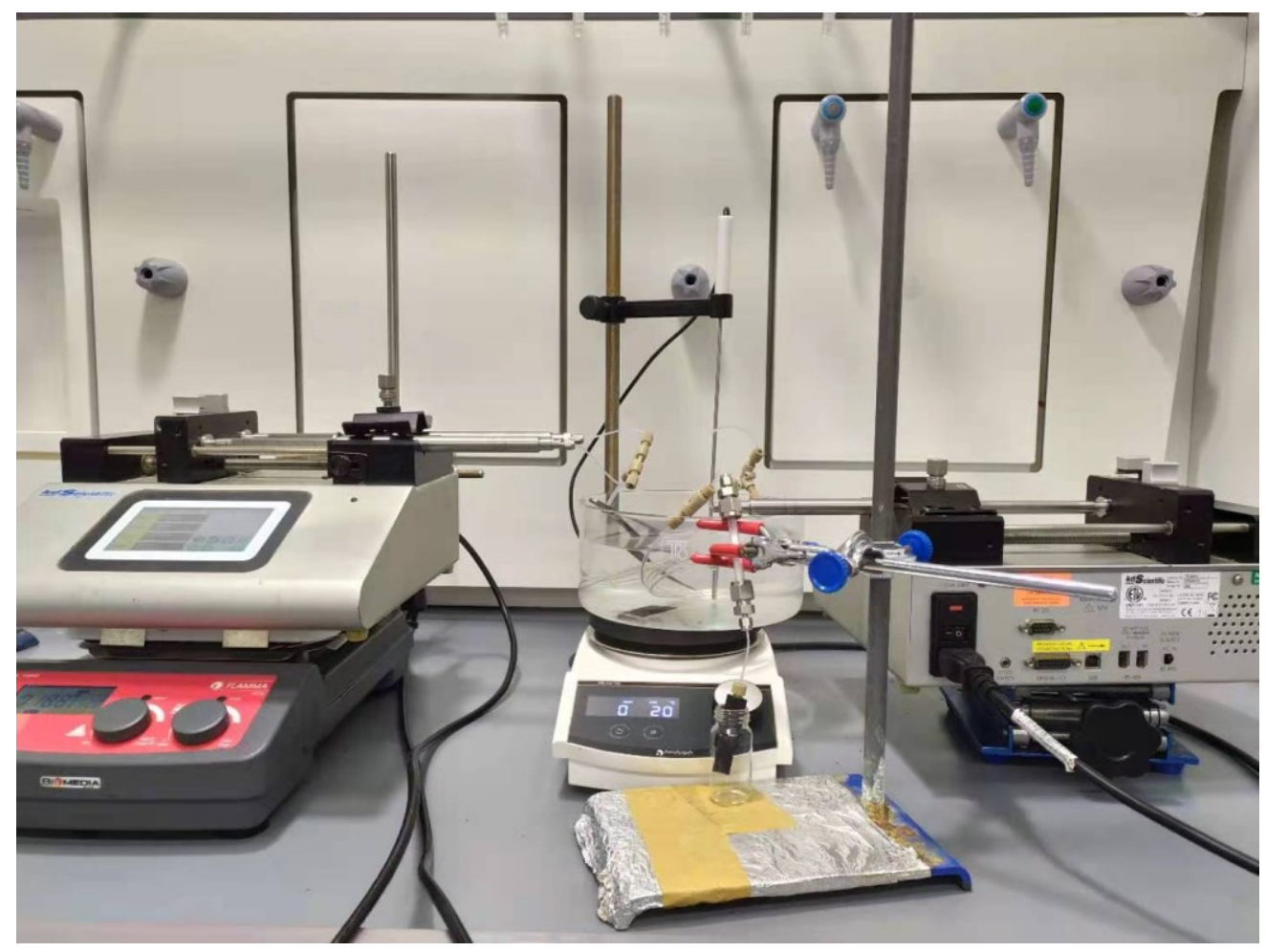

Figure S4. General flow set-up for testing substrates in small scale. The pump on the left was used for pumping substrates and catalyst, while the pump on the right was used to pump SnatchCat for the workup. At the end of the reaction, the residues were filtered through the silica gel packed bed and collected in the $20 \mathrm{~mL}$ glass vial.

\section{Procedure for RCM Reaction of Pacritinib Precursor in Flow}

The precursor of Pacritinib 17 (30 mg, $0.064 \mathrm{mmol}, 1$ equiv.) and catalyst Ru2 (4.3 mg, 0.005 mmol, $8.0 \mathrm{~mol} \%$ ) were weighed separately, put into two different $20 \mathrm{~mL}$ vials (preheated in the oven for at least $30 \mathrm{~min}$ ), and covered with rubber septum caps tightly. Atmosphere exchange was done employing argon (as inert gas) using vacuum pumps (three cycles were performed before attaching balloons filled with argon to each of the vials). Then, $8 \mathrm{~mL}$ of dried and argonbubbled EtOAc was transferred into the vials via a syringe and sonication was done to ensure that all the catalyst and substrate were fully dissolved. Afterwards, $10 \mu \mathrm{L}$ of trifluoroacetic acid (15 mg, 0.135 mmol, 2.1 equiv.) was added to the Pacritinib precursor solution in order to acidify the free amine groups in the starting material via a micro-syringe.

Using an $8 \mathrm{~mL}$ KDS stainless syringe attached with a needle connector (Figure S1), the acidified Pacritinib solution mixture was extracted from the $20 \mathrm{~mL}$ vial and connected to a KDS syringe pump. Another $8 \mathrm{~mL}$ KDS stainless syringe was filled with the Ru2 solution mixture and attached to the same KDS syringe pump. Meanwhile, solid SnatchCat (5.0 mg, $0.023 \mathrm{mmol}, 35.2 \mathrm{~mol} \%, 4.4$ equiv. vs the catalyst) was dissolved in $8 \mathrm{~mL}$ of untreated EtOAc and extracted into an $8 \mathrm{~mL}$ KDS stainless syringe. Likewise, the syringe was attached to a KDS syringe pump. The flow setup was as shown in Scheme S3 with the tubing soaked in an oil bath at $90{ }^{\circ} \mathrm{C}$ to provide heating for the reaction. After 2 residence timing ( $\left.t_{R}\right)$ of 40 minutes, the product was collected at the end of the silica packed bed and concentrated under vacuum. Concentrated sodium carbonate 
solution was used to neutralize the product via liquid-liquid extraction. The organic layer was concentrated and purified using flash column chromatography (stationary phase: $\mathrm{SiO}_{2}$, eluent: EtOAc/ $n$-hexane 20:80 v/v) to obtain the desired RCM product $18(72 \%, E / Z=66: 34)$. Further analysis was performed using NMR and ICP-OES (<15 ppm of Ru).

\section{Procedure for RCM Reaction of Sildenafil Derivative in Flow in Larger Scale}

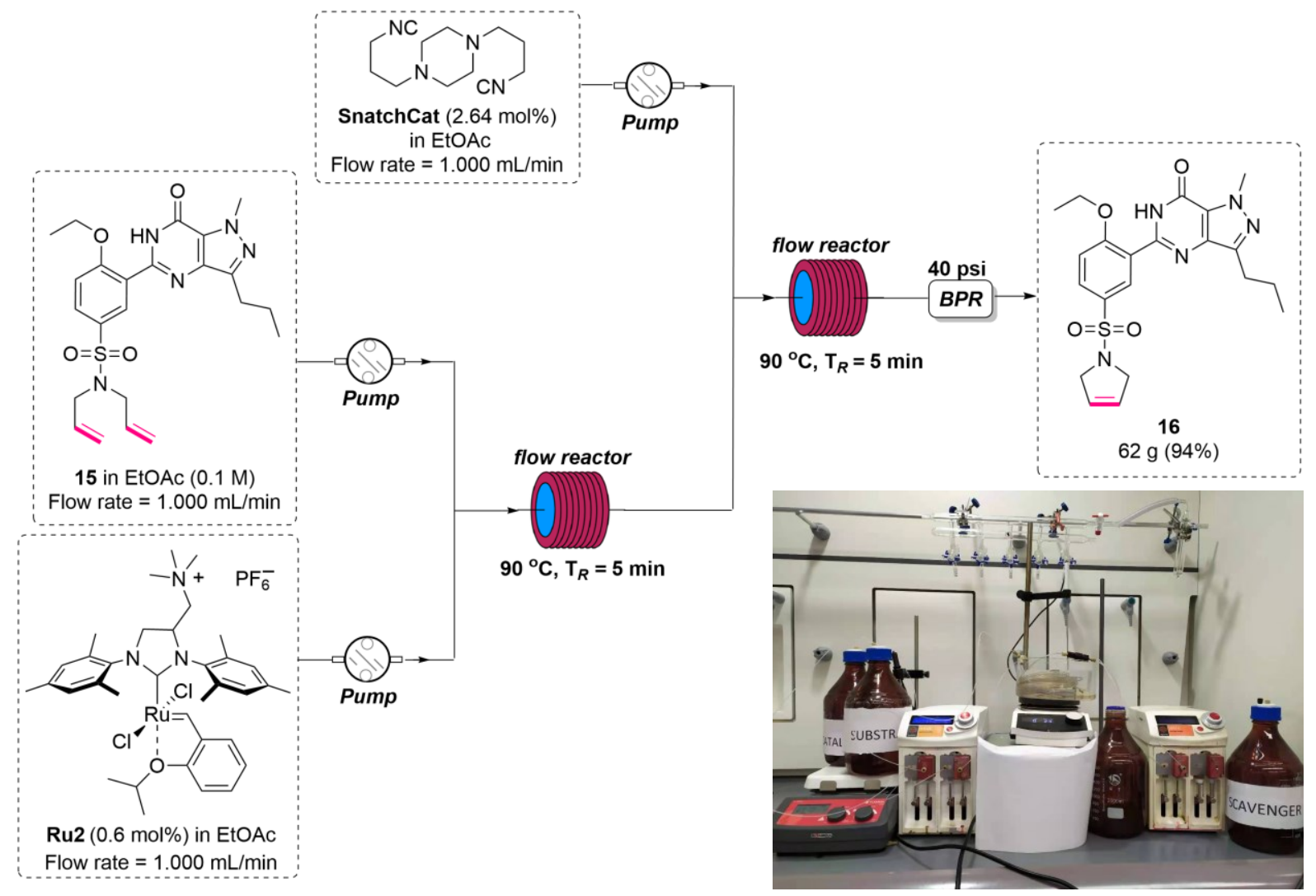

Scheme S4. Flow set-up diagram for the synthesis of Sildenafil derivative in a 24-hour flow system.

Sildenafil derivative 15 (72.84 g, 150 mmol, 1 equiv.) and catalyst Ru2 (759.6 mg, 0.9 mmol, 0.3 mol\%) were weighed separately, put into two different $2.5 \mathrm{~L}$ blue capped bottles (preheated in the oven for at least $30 \mathrm{~min}$ ), and tightened with the blue cap shown in Figure S1. The starting materials were purged with argon gas for 10 minutes to remove any residual air in the bottle. Subsequently, $1.5 \mathrm{~L}$ of dried and argon-bubbled EtOAc was transferred into the bottles and sonicated until all the catalyst and substrate were fully dissolved into the solvent.

The two large bottles were connected to an Asia pump which was connected to the reaction tubing. Meanwhile, SnatchCat scavenger $(871.2 \mathrm{mg}, 3.96 \mathrm{mmol}, 1.32 \mathrm{~mol} \%$, 4.4 equiv. vs the catalyst) was dissolved in $1.5 \mathrm{~L}$ of EtOAc and connected to another Asia pump (shown in Scheme S4 and Figure S5). The flow set-up was illustrated in Scheme S4 with the tubing soaked in an oil bath at $90{ }^{\circ} \mathrm{C}$ to provide heating for the reaction. After 2 residence timing $\left(t_{R}\right)$ of 20 minutes, the product was collected at the end. The post-reaction mixture was being collected for 24 hours and then purified using flash column chromatography (stationary phase: $60 \mathrm{~g}$ of $\mathrm{SiO}_{2}$, eluent: EtOAc). The product solution was concentrated under vacuum to furnish product 16 (62 g, 94\%). The product was analyzed using NMR and ICP-MS (0.51 ppm of Ru). 


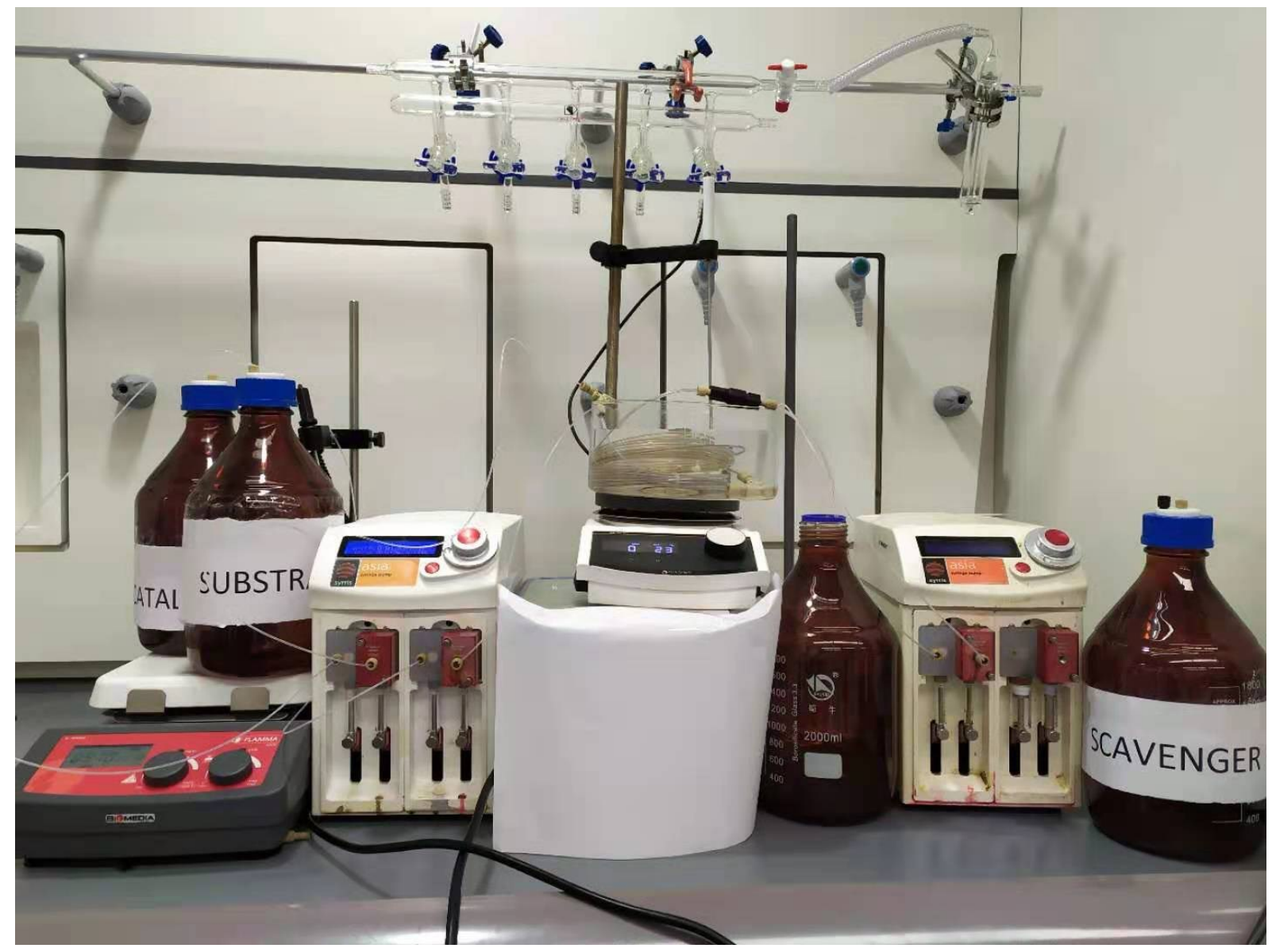

Figure S5. Actual flow set-up for the synthesis of Sildenafil derivative 16 in a 24-hour flow system with two Asia pumps. 


\section{Analytical Data}

Diethyl cyclopent-3-ene-1,1-dicarboxylate $(2)^{1}$

$\mathrm{EtO}_{2} \mathrm{C} \mathrm{CO}_{2} \mathrm{Et}$ Colorless liquid purified using column chromatography (stationary phase: $\mathrm{SiO}_{2}$, eluent: $\mathrm{EtOAc} / n$-hexane 10:90 v/v).

${ }^{1} \mathrm{H}$ NMR (400 MHz, $\mathrm{CDCl}_{3}$ ) $\delta: 5.61(\mathrm{~s}, 2 \mathrm{H}), 4.20$ (q, $\left.J=7.1 \mathrm{~Hz}, 4 \mathrm{H}\right), 3.01$ (s, $4 \mathrm{H}), 1.25(\mathrm{t}, J=7.1 \mathrm{~Hz}, 6 \mathrm{H})$.

${ }^{13} \mathrm{C}$ NMR (101 MHz, $\left.\mathrm{CDCl}_{3}\right) \delta: 172.2,127.8,61.5,58.8,40.8,14.0$.

Benzyl 2-methyl-2,3,4,7-tetrahydro-1H-azepine-1-carboxylate $(4)^{2}$

$\mathrm{Cbz}$ Colorless liquid purified using column chromatography (stationary phase: $\mathrm{SiO}_{2}$, eluent: EtOAc/n-hexane 5:95 v/v).

${ }^{1} \mathrm{H}$ NMR (400 MHz, $\left.\mathrm{CDCl}_{3}\right) \delta: 7.39-7.28(\mathrm{~m}, 5 \mathrm{H}), 5.68(\mathrm{dt}, J=9.6,5.6 \mathrm{~Hz}, 2 \mathrm{H}), 5.20-$ $5.09(\mathrm{~m}, 2 \mathrm{H}), 4.47-4.06(\mathrm{~m}, 2 \mathrm{H}), 3.65-3.56(\mathrm{~m}, 1 \mathrm{H}), 2.27-2.07(\mathrm{~m}, 2 \mathrm{H}), 1.93-1.66(\mathrm{~m}$, $2 \mathrm{H}), 1.14(\mathrm{dd}, J=6.4,3.6 \mathrm{~Hz}, 3 \mathrm{H})$.

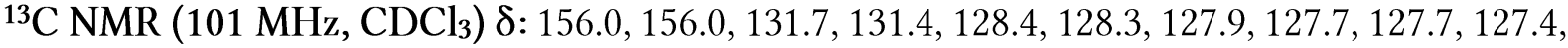
$66.9,66.7,52.5,52.3,39.4,39.1,34.0,33.9,27.2,26.9,19.6,19.2$.

1-Benzylcyklohept-4-en-1-ol $(6)^{3}$

$\mathrm{Ph} \mathrm{OH}$ Colorless liquid purified using column chromatography (stationary phase: $\mathrm{SiO}_{2}$, eluent: EtOAc/n-hexane 20:80 v/v).

${ }^{1} \mathrm{H}$ NMR (400 MHz, $\left.\mathrm{CDCl}_{3}\right) \delta: 7.38-7.31(\mathrm{~m}, 2 \mathrm{H}), 7.29-7.19(\mathrm{~m}, 3 \mathrm{H}), 5.76(\mathrm{qt}$, $J=10.6,4.5 \mathrm{~Hz}, 2 \mathrm{H}), 2.92-2.73(\mathrm{~m}, 2 \mathrm{H}), 2.36-2.00(\mathrm{~m}, 2 \mathrm{H}), 2.09-1.97(\mathrm{~m}, 2 \mathrm{H})$, $1.71-1.67(\mathrm{~m}, 2 \mathrm{H}), 1.37(\mathrm{~d}, J=12.5 \mathrm{~Hz}, 1 \mathrm{H})$.

${ }^{13} \mathrm{C}$ NMR (101 MHz, $\left.\mathrm{CDCl}_{3}\right) \delta: 137.2,131.6,130.7,128.2,126.5,74.9,48.5,38.5,23.0$.

1-Phenylcyclopent-3-ene-1-carboxylic acid $(8)^{4}$

$\mathrm{Ph} \mathrm{CO}_{2} \mathrm{H}$ Colorless solid purified using column chromatography (stationary phase: $\mathrm{SiO}_{2}$, eluent: EtOAc/n-hexane 60:40 v/v).

${ }^{1} \mathrm{H}$ NMR $\left(400 \mathrm{MHz}, \mathrm{CDCl}_{3}\right) \delta: 7.51-7.20(\mathrm{~m}, 5 \mathrm{H}), 5.78(\mathrm{~d}, J=7.9 \mathrm{~Hz}, 2 \mathrm{H}), 3.56$ $-3.37(\mathrm{~m}, 2 \mathrm{H}), 2.87-2.71(\mathrm{~m}, 2 \mathrm{H})$.

${ }^{13} \mathrm{C}$ NMR (101 MHz, $\left.\mathrm{CDCl}_{3}\right) \delta:$ 182.6, 142.7, 129.2, 128.5, 127.1, 127.0, 58.4, 42.3.

1-(Tosylpropyl)-2,5-dihydro-1H-pyrrole $(\mathbf{1 0})^{5}$

$\square$ Colorless crystals purified using column chromatography (stationary phase: $\mathrm{SiO}_{2}$, eluent: EtOAc/n-hexane 20:80 v/v).

${ }^{1} \mathrm{H}$ NMR (400 MHz, $\left.\mathrm{CDCl}_{3}\right) \delta: 7.80-7.70(\mathrm{~m}, 2 \mathrm{H}), 7.32-7.24(\mathrm{~m}, 2 \mathrm{H}), 5.90-$ $5.76(\mathrm{~m}, 2 \mathrm{H}), 4.65-4.52(\mathrm{~m}, 2 \mathrm{H}), 4.35-4.10(\mathrm{~m}, 3 \mathrm{H}), 3.43(\mathrm{qdd}, J=9.6,7.3,6.1$ $\mathrm{Hz}, 2 \mathrm{H}), 2.40(\mathrm{~s}, 3 \mathrm{H}), 2.18-1.89(\mathrm{~m}, 3 \mathrm{H}), 1.85-1.71(\mathrm{~m}, 1 \mathrm{H})$.

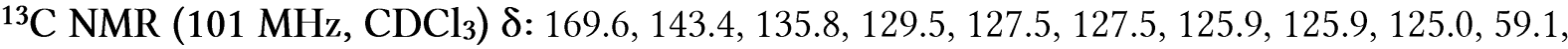
$53.4,53.1,48.3,30.3,24.9,24.9,21.5$. 
2-(Benzhydrylthio)-1-(2,5-dihydro-1H-pyrrol-1-yl)ethan-1-one (12) ${ }^{6}$

$\mathrm{Ph}$ Colorless crystals purified using column chromatography (stationary phase: $\mathrm{SiO}_{2}$, eluent: EtOAc/n-hexane 25:75 v/v).

${ }^{1} \mathrm{H}$ NMR (400 MHz, $\left.\mathrm{CDCl}_{3}\right) \delta: 7.51-7.42(\mathrm{~m}, 4 \mathrm{H}), 7.36-7.18(\mathrm{~m}, 6 \mathrm{H}), 5.88$ - $5.79(\mathrm{~m}, 1 \mathrm{H}), 5.77-5.69(\mathrm{~m}, 1 \mathrm{H}), 5.47(\mathrm{~s}, 1 \mathrm{H}), 4.24-4.11(\mathrm{~m}, 4 \mathrm{H}), 3.11(\mathrm{~s}$, $2 \mathrm{H})$.

${ }^{13} \mathrm{C}$ NMR (101 MHz, $\left.\mathrm{CDCl}_{3}\right) \delta: 167.2,140.7,128.6,128.5,127.3,126.1,124.9,53.5,53.4,53.2$, 34.0.

2-(Benzhydrylsulfinyl)-1-(2,5-dihydro-1H-pyrrol-1-yl)ethan-1-one (14) ${ }^{6}$<smiles>O=C(CS(=O)C(c1ccccc1)c1ccccc1)N1CC=CC1</smiles>

Colorless crystals purified using column chromatography (stationary phase: $\mathrm{SiO}_{2}$, eluent: EtOAc/n-hexane 40:60 v/v).

${ }^{1} \mathrm{H}$ NMR $\left(400 \mathrm{MHz}, \mathrm{CDCl}_{3}\right) \delta: 7.58-7.49(\mathrm{~m}, 4 \mathrm{H}), 7.35(\mathrm{dq}, J=20.1,7.1 \mathrm{~Hz}$, $6 \mathrm{H}), 5.80(\mathrm{dq}, J=6.5,2.1 \mathrm{~Hz}, 1 \mathrm{H}), 5.68(\mathrm{dt}, J=6.5,2.1 \mathrm{~Hz}, 1 \mathrm{H}), 5.44(\mathrm{~s}, 1 \mathrm{H})$, $4.28-4.13(\mathrm{~m}, 3 \mathrm{H}), 4.01(\mathrm{ddq}, J=14.0,5.0,2.3 \mathrm{~Hz}, 1 \mathrm{H}), 3.48(\mathrm{~d}, J=2.5 \mathrm{~Hz}$,

$2 \mathrm{H})$.

${ }^{13} \mathrm{C}$ NMR (101 MHz, $\left.\mathrm{CDCl}_{3}\right) \delta: 162.9,136.0,133.7,130.0,129.1,129.0,128.7,128.5,128.2,125.8$, $124.8,77.5,77.4,77.2,76.9,69.7,53.9,53.7,53.1$.

5-(5-((2,5-Dihydro-1H-pyrrol-1-yl)sulfonyl)-2-ethoxyphenyl)-1-methyl-3-propyl-1,6-dihydro7H-pyrazolo[4,3-d]pyrimidin-7-one $(16)^{7}$

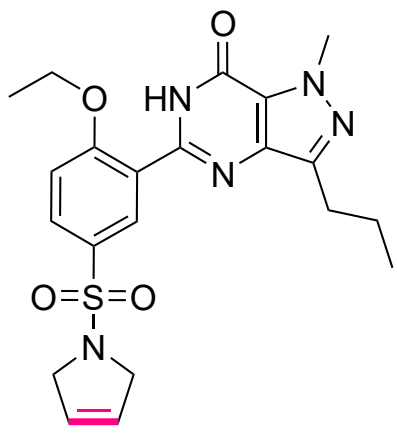

Colorless crystals purified using column chromatography (stationary phase: $\mathrm{SiO}_{2}$, eluent: $\mathrm{EtOAc} / n$-hexane 60:40 v/v).

${ }^{1} \mathrm{H}$ NMR $\left(400 \mathrm{MHz}, \mathrm{CDCl}_{3}\right) \delta: 10.88(\mathrm{~s}, 1 \mathrm{H}), 8.80(\mathrm{~d}, J=2.4 \mathrm{~Hz}, 1 \mathrm{H})$, $7.85(\mathrm{dd}, J=8.8,2.4 \mathrm{~Hz}, 1 \mathrm{H}), 7.12(\mathrm{~d}, J=8.8 \mathrm{~Hz}, 1 \mathrm{H}), 5.66(\mathrm{~s}, 2 \mathrm{H}), 4.33$ $(\mathrm{q}, J=7.0 \mathrm{~Hz}, 2 \mathrm{H}), 4.22(\mathrm{~s}, 3 \mathrm{H}), 4.14(\mathrm{~s}, 4 \mathrm{H}), 2.89(\mathrm{dd}, J=8.0,7.1 \mathrm{~Hz}$, $2 \mathrm{H}), 1.89-1.76(\mathrm{~m}, 2 \mathrm{H}), 1.59(\mathrm{t}, J=7.0 \mathrm{~Hz}, 3 \mathrm{H}), 0.99(\mathrm{t}, J=7.4 \mathrm{~Hz}$, $3 \mathrm{H})$.

${ }^{13} \mathrm{C}$ NMR (101 MHz, $\left.\mathrm{CDCl}_{3}\right) \delta: 159.2,153.6,146.9,146.6,138.3$, $131.3,130.7,130.5,125.5,124.4,121.1,113.2,66.0,55.0,38.2,27.7,22.3$, $14.5,14.0$.

44-(2-Chloroethoxy)-6,11-dioxa-3-aza-2(4,2)-pyrimidina-1,4(1,3)-dibenzenacyclododecaphan-8ene $(18)^{8}$<smiles>ClCCOc1ccc(Nc2nccc(-c3cccc(COC/C=C/COCc4ccccc4)c3)n2)cc1</smiles>

Yellow solid purified using column chromatography (stationary phase: $\mathrm{SiO}_{2}$, eluent: $\mathrm{EtOAc} / n$-hexane 15:85 to 20:80 v/v).

${ }^{1} \mathrm{H}$ NMR $\left(400 \mathrm{MHz}, \mathrm{CD}_{2} \mathrm{Cl}_{2}\right) \delta: 8.64(\mathrm{~d}, J=1.7 \mathrm{~Hz}, 1 \mathrm{H}), 8.51-8.38$ $(\mathrm{m}, 1 \mathrm{H}), 8.26(\mathrm{~d}, J=1.8 \mathrm{~Hz}, 1 \mathrm{H}), 7.84(\mathrm{dt}, J=7.7,1.6 \mathrm{~Hz}, 1 \mathrm{H}), 7.61$ - 7.57 (m, 1H), $7.53-7.46(\mathrm{~m}, 1 \mathrm{H}), 7.29$ (br, 1H), 7.20 (d, $J=5.0$ $\mathrm{Hz}, 1 \mathrm{H}), 6.90-6.86(\mathrm{~m}, 2 \mathrm{H}), 5.91-5.66(\mathrm{~m}, 2 \mathrm{H}), 4.68-4.56(\mathrm{~m}$, $4 \mathrm{H}), 4.29-4.24(\mathrm{~m}, 2 \mathrm{H}), 4.13(\mathrm{~d}, J=5.8 \mathrm{~Hz}, 2 \mathrm{H}), 4.04(\mathrm{dd}, J=5.4$, $1.0 \mathrm{~Hz}, 2 \mathrm{H}), 3.86(\mathrm{td}, J=5.9,0.9 \mathrm{~Hz}, 2 \mathrm{H})$.

${ }^{13} \mathrm{C}$ NMR $\left(101 \mathrm{MHz}, \mathrm{CD}_{2} \mathrm{Cl}_{2}\right) \delta: 164.5,160.7,159.3,151.8,139.4,137.5,134.4,132.2,131.3,130.4$, 129.3, 127.8, 126.6, 121.7, 119.5, 114.0, 108.4, 70.5, 70.0, 69.7, 68.0, 65.9, 43.0. 


\section{GC Quantification Details}

Measurements were carried out at National University of Singapore. Sample preparation was done by measuring $5 \mathrm{mg}$ of the starting material (substrates) into GC vials. A standard stock solution of $56.0 \mathrm{mg}$ of 1,3,5-trimethoxybenzene was measured and added with $10 \mathrm{~mL}$ of EtOAc as solvent. For each substrate, $1.5 \mathrm{~mL}$ of the stock solution was added to it and measured with a GC using temperature programming. The $K$ value of the ratio between the internal standard and substrate was obtained. In addition, the retention time of the substrate was obtained. Subsequently, $5 \mathrm{mg}$ of product sample was measured and added with $1.5 \mathrm{~mL}$ of standard stock solution. The amount of the starting material was calculated with reference to the internal standard and $K$ value. Then, the mass of both starting material and product was calculated before converting to moles for the conversion.

\section{ICP-OES Measurement Details}

Approximately $100 \mathrm{mg}$ of the product was extracted after reaction in flow system, introduced into PTFE vessels and topped up with $3 \mathrm{~mL}$ of Supra Pure nitric acid (65\%). The vessels were capped and placed in a microwave digester to decompose the organic substances. The microwave was heated up to $180{ }^{\circ} \mathrm{C}$ at $500 \mathrm{~W}$ for $15-30 \mathrm{~min}$. The temperature was then fixed at $180{ }^{\circ} \mathrm{C}$ and $500 \mathrm{~W}$ for $10 \mathrm{~min}$. The digested substances were then left to cool to room temperature before transferring to a $25 \mathrm{~mL}$ or $50 \mathrm{~mL}$ volumetric flasks and topping up with ultra-pure water.

Standard calibration curve was plotted with commercially available standards which are diluted to $0,1,10,100,250,500$ and $1000 \mathrm{ppb}$. Ruthenium concentrations of the samples were then determined by ICP-OES from this standard calibration curve. The concentration obtained, in parts per billion (ppb), from ICP-OES was multiplied by the dilution factor of 25 and divided by the mass (measured beforehand). Example results: $9.094 \mathrm{ppb}$ signal in the ICP-OES concluded that in $101.66 \mathrm{mg}$ sample, there was 2.2 parts per million (ppm) of ruthenium present. 


\section{${ }^{1} \mathrm{H}$ and ${ }^{13} \mathrm{C}$ NMR Spectra}

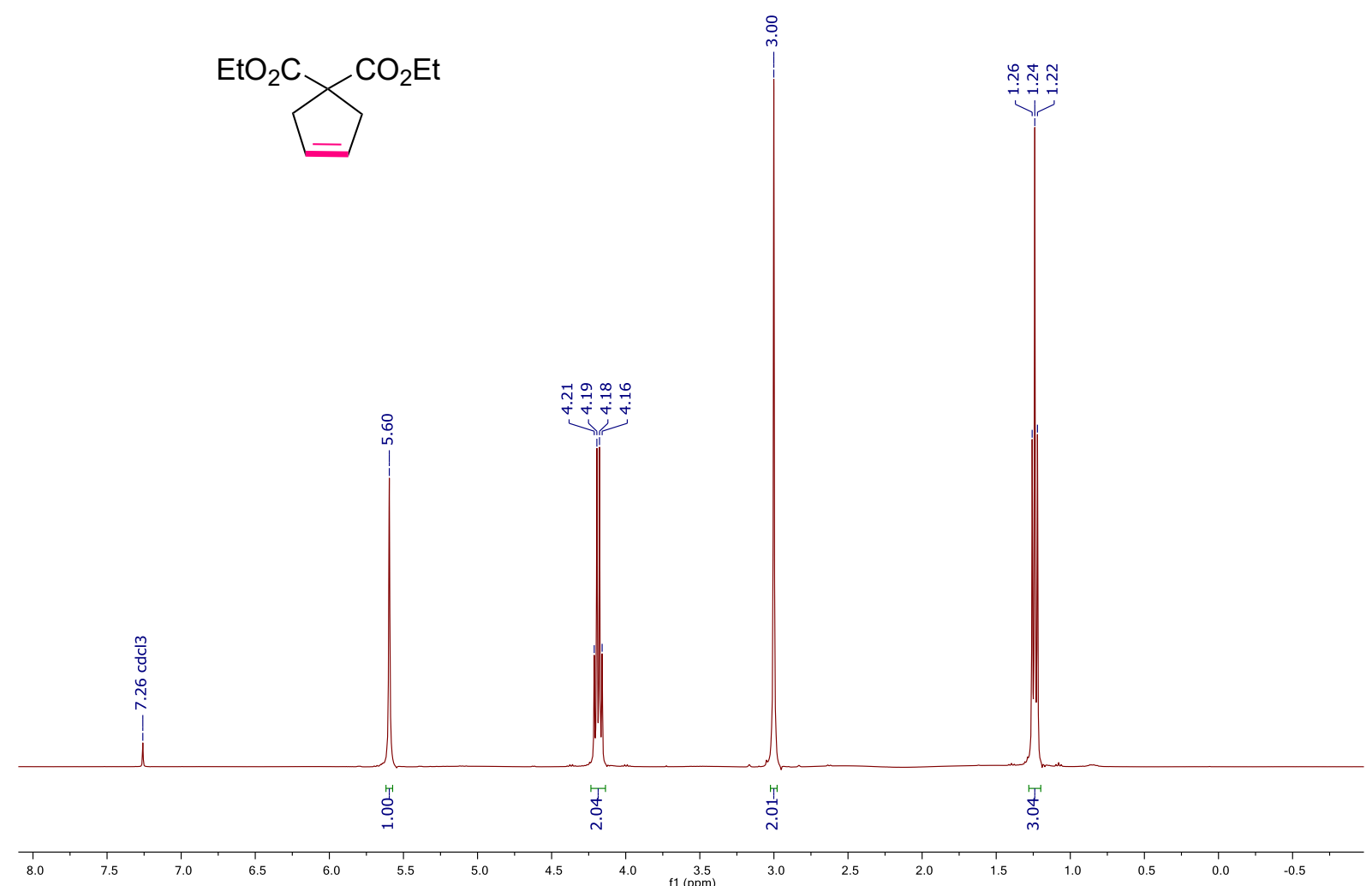

Figure S6. ${ }^{1} \mathrm{H}$ NMR of diethyl cyclopent-3-ene-1,1-dicarboxylate (2).

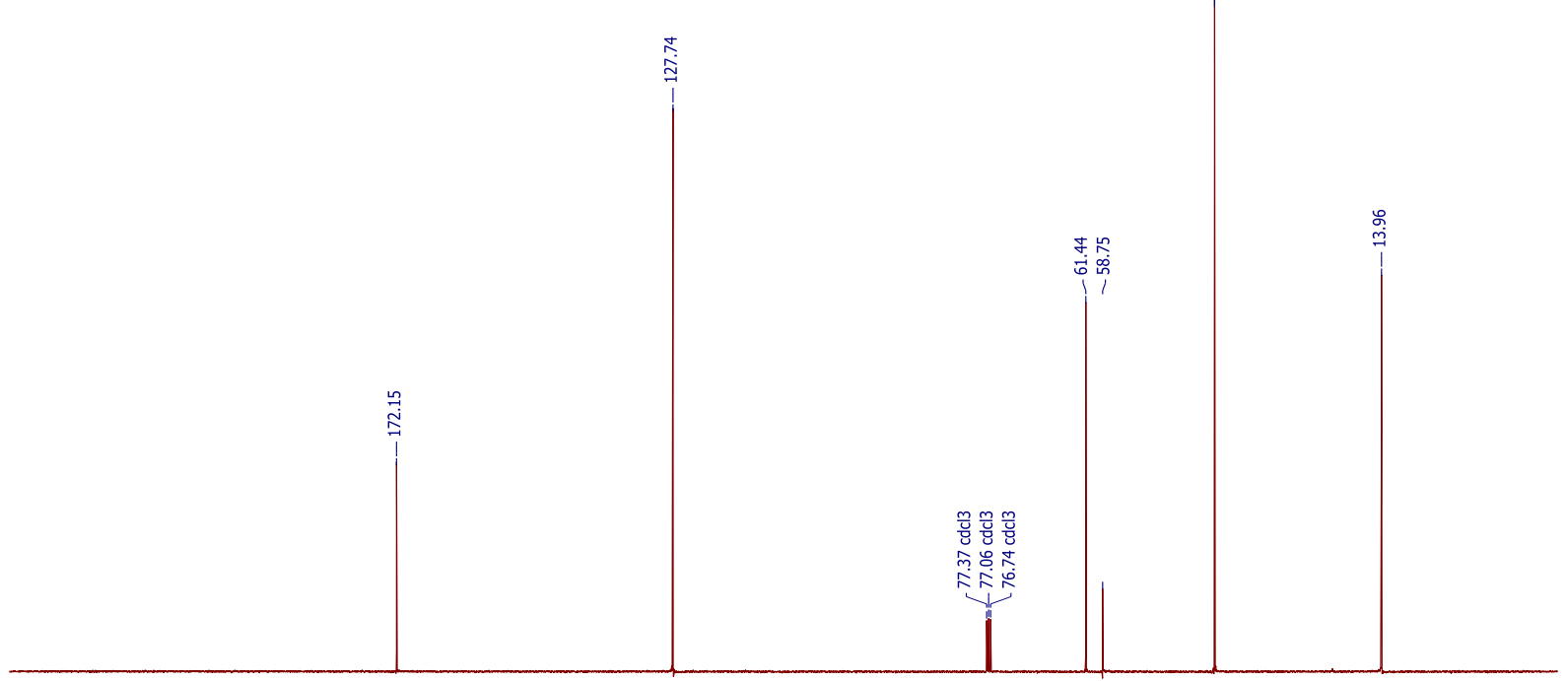

Figure S7. ${ }^{13} \mathrm{C}$ NMR of diethyl cyclopent-3-ene-1,1-dicarboxylate (2). 


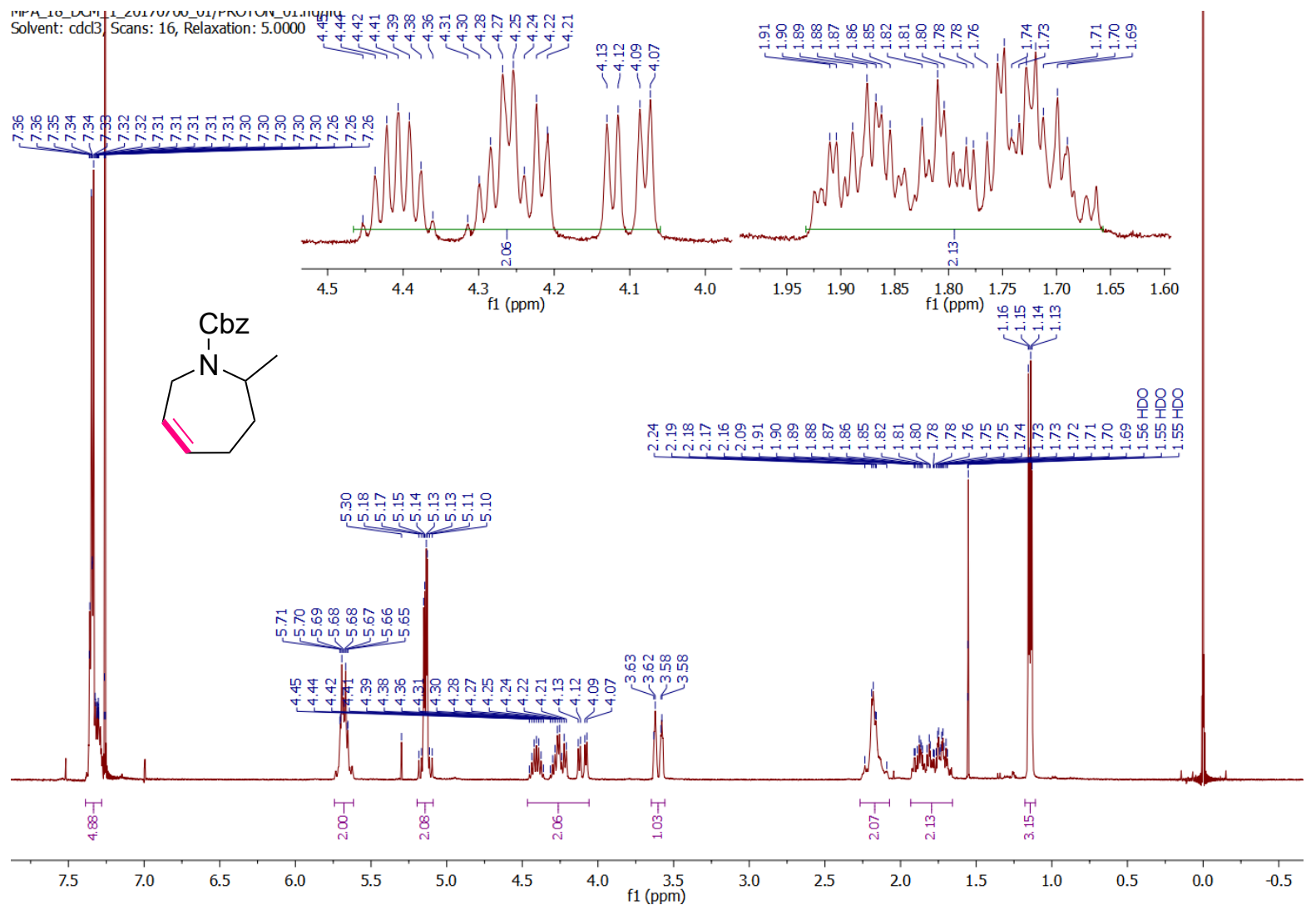

Figure S8. ${ }^{1} \mathrm{H}$ NMR of benzyl 2-methyl-2,3,4,7-tetrahydro-1H-azepine-1-carboxylate (4).

Solvent: cdcl3, Scans: 256, Relaxation: 5.0000

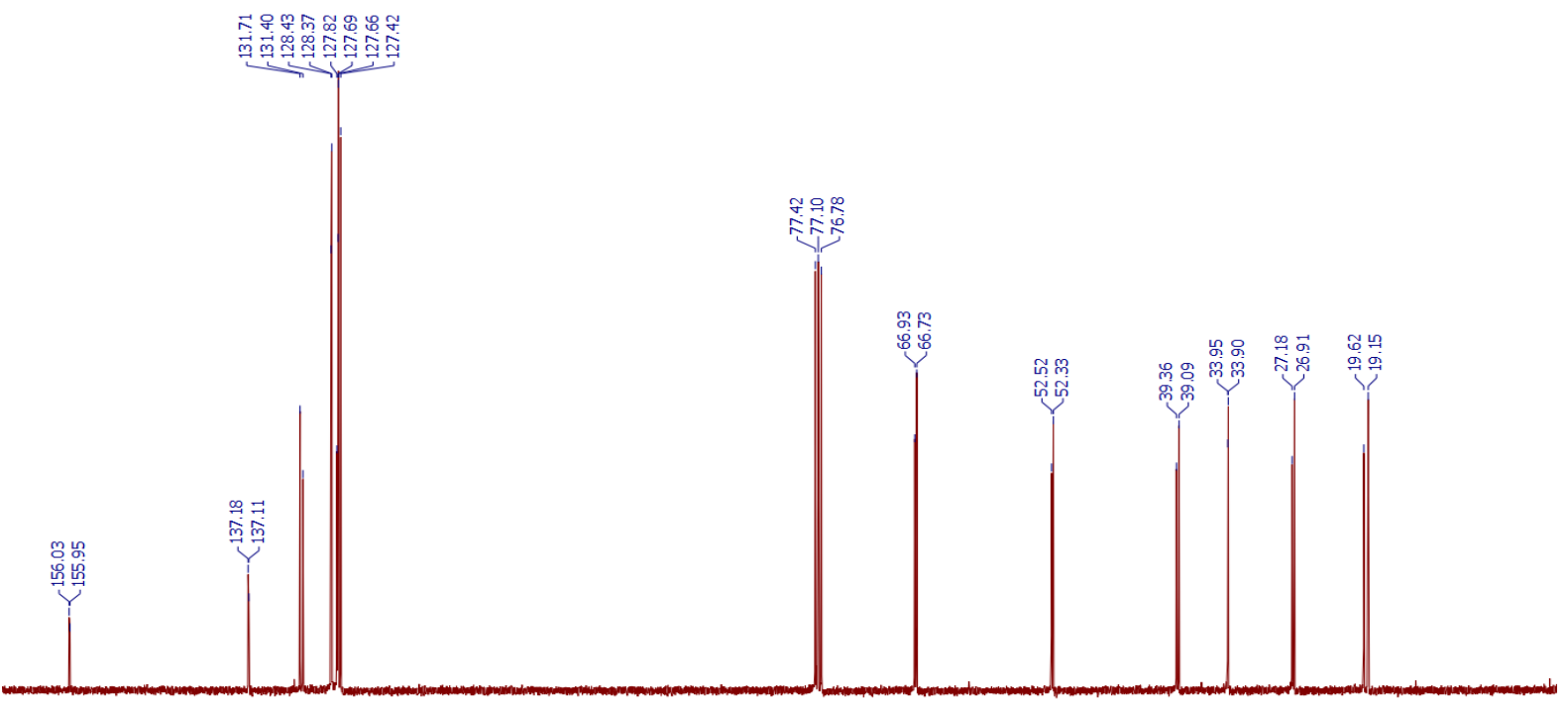

Figure S9. ${ }^{13} \mathrm{C}$ NMR of benzyl 2-methyl-2,3,4,7-tetrahydro-1H-azepine-1-carboxylate (4). 
<smiles>OC1(Cc2ccccc2)CCC=CCC1</smiles>

总

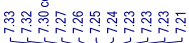

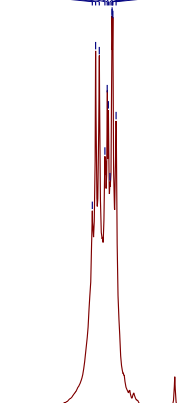

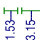

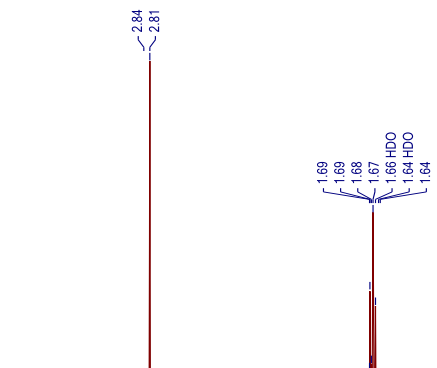

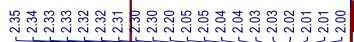

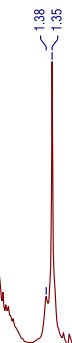

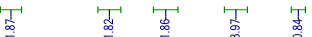

Figure S10. ${ }^{1} \mathrm{H}$ NMR of 1-benzylcyklohept-4-en-1-ol (6).

MPA_CBEN_20180714_01/CARBON_01.fid/fid Solvent: cdcl3, Scans: 256, Relaxation: 3.0000
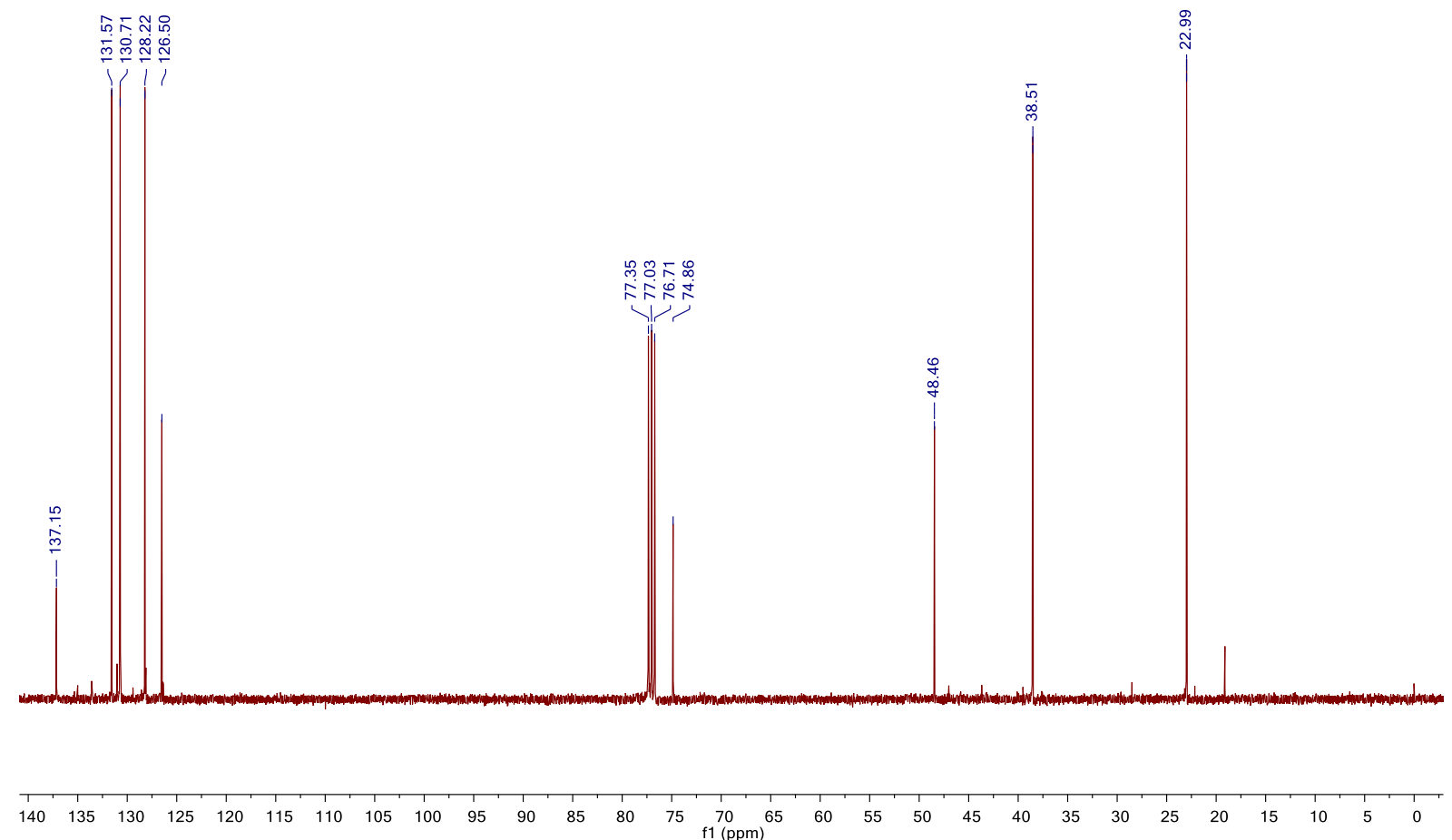

Figure S11. ${ }^{13} \mathrm{C}$ NMR of 1-benzylcyklohept-4-en-1-ol(6). 


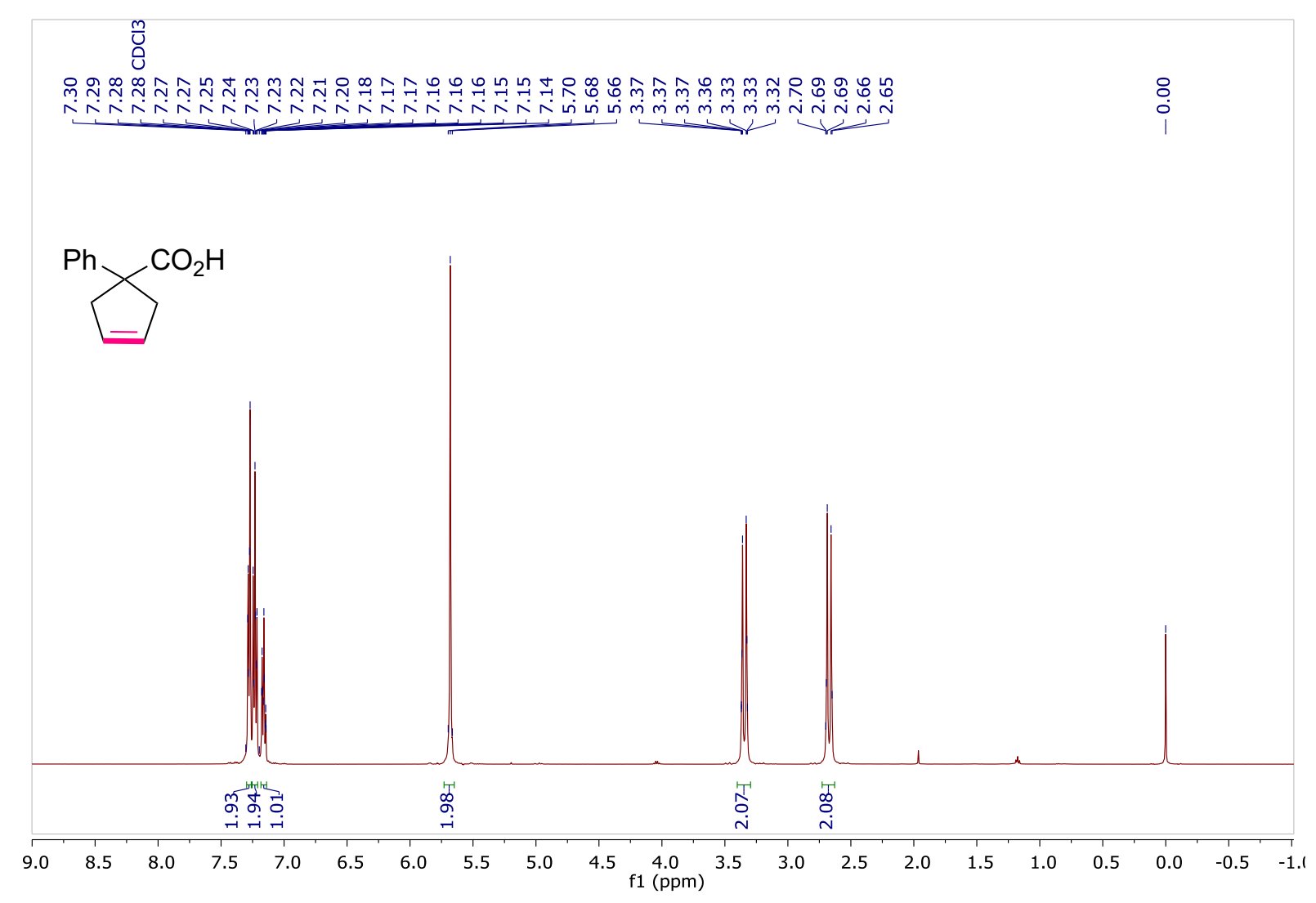

Figure S12. ${ }^{1} \mathrm{H}$ NMR of 1-phenylcyclopent-3-ene-1-carboxylic acid (8).

MPA_CPEN_20180714_01/CARBON_01.fid/fid Solvent: cdcl3, Scans: 256, Relaxation: 3.0000
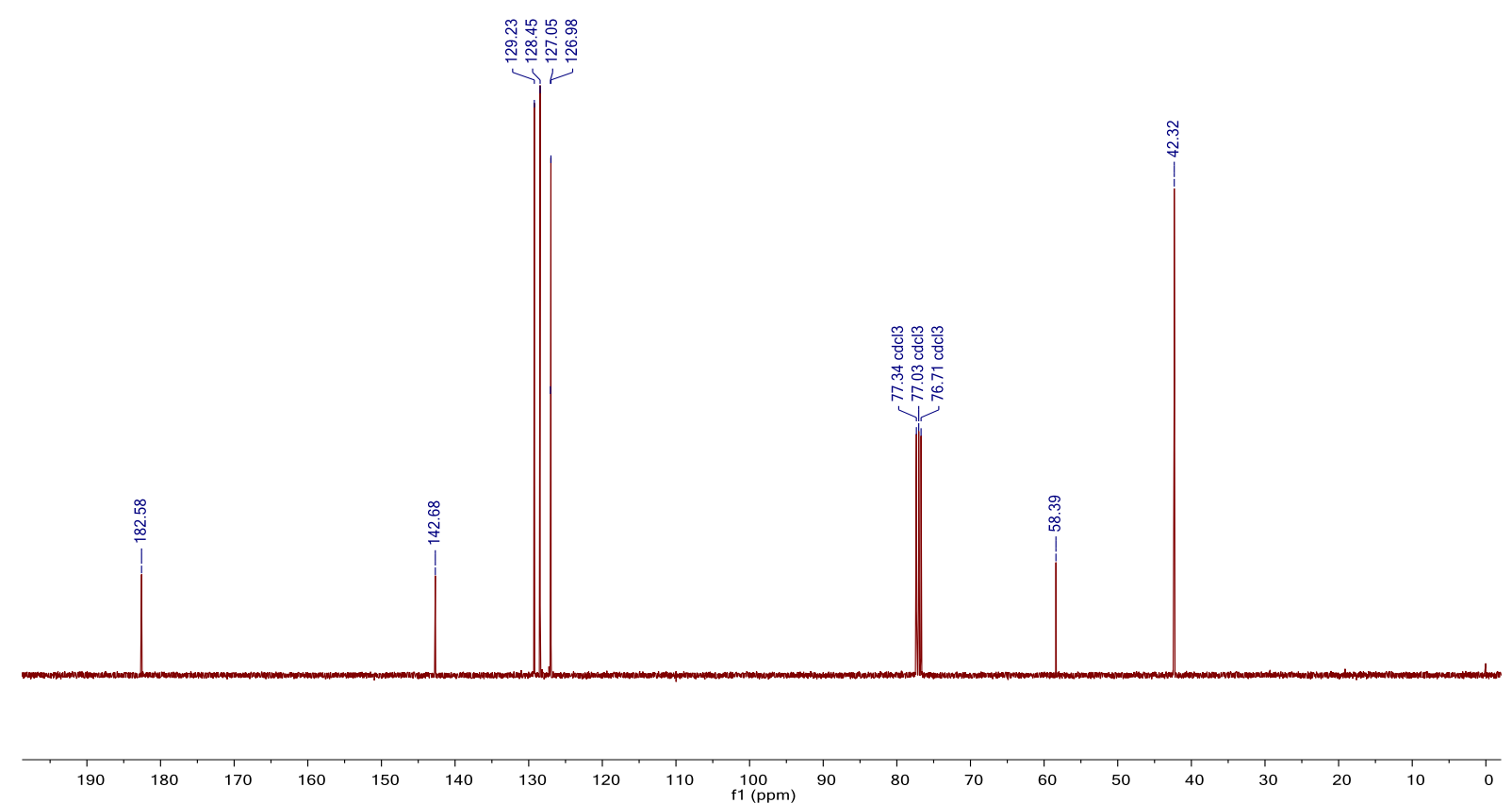

Figure S13. ${ }^{13} \mathrm{C}$ NMR of 1-phenylcyclopent-3-ene-1-carboxylic acid(8). 

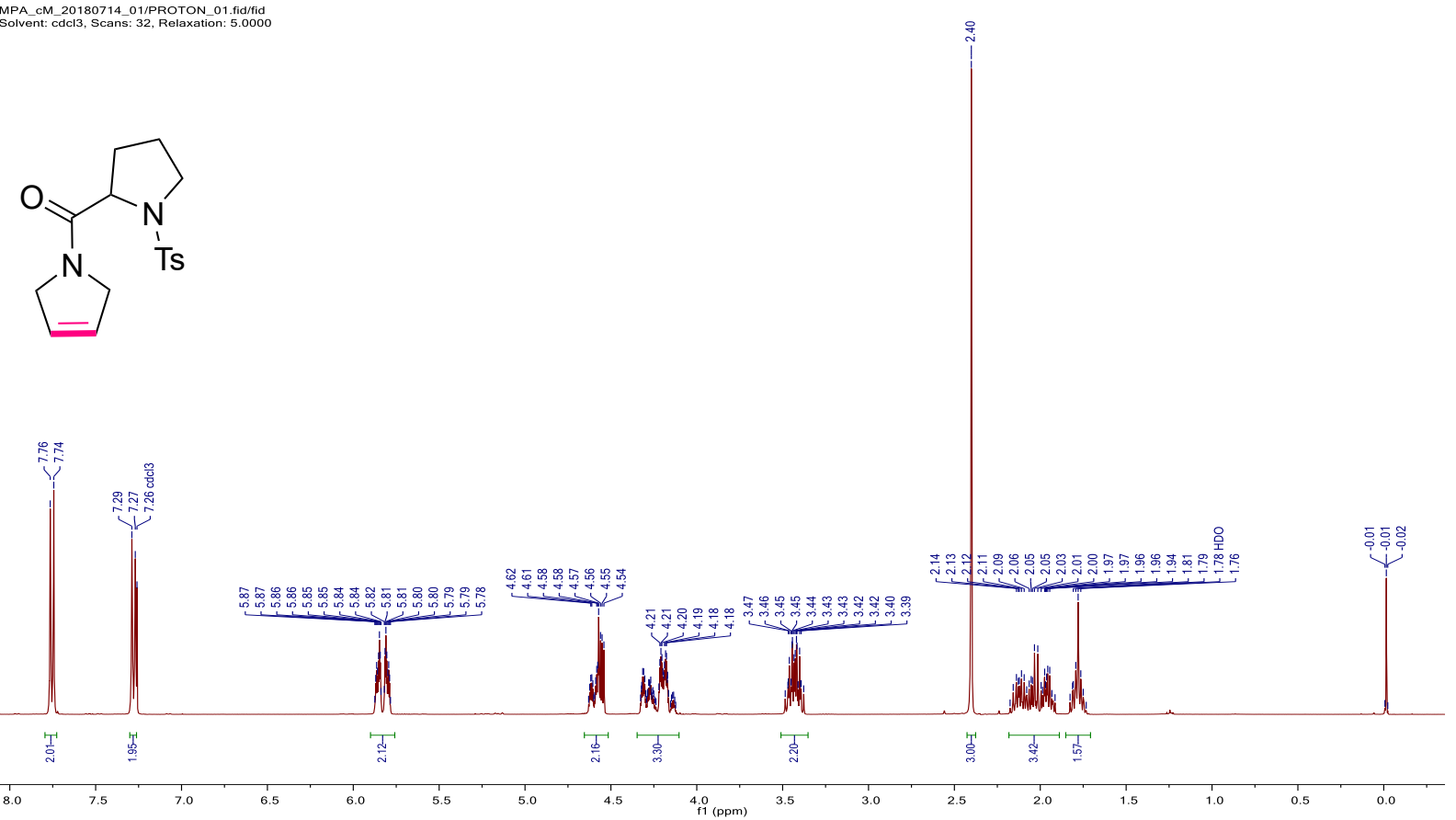

Figure S14. ${ }^{1} \mathrm{H}$ NMR of 1-(tosylpropyl)-2,5-dihydro-1H-pyrrole (10).
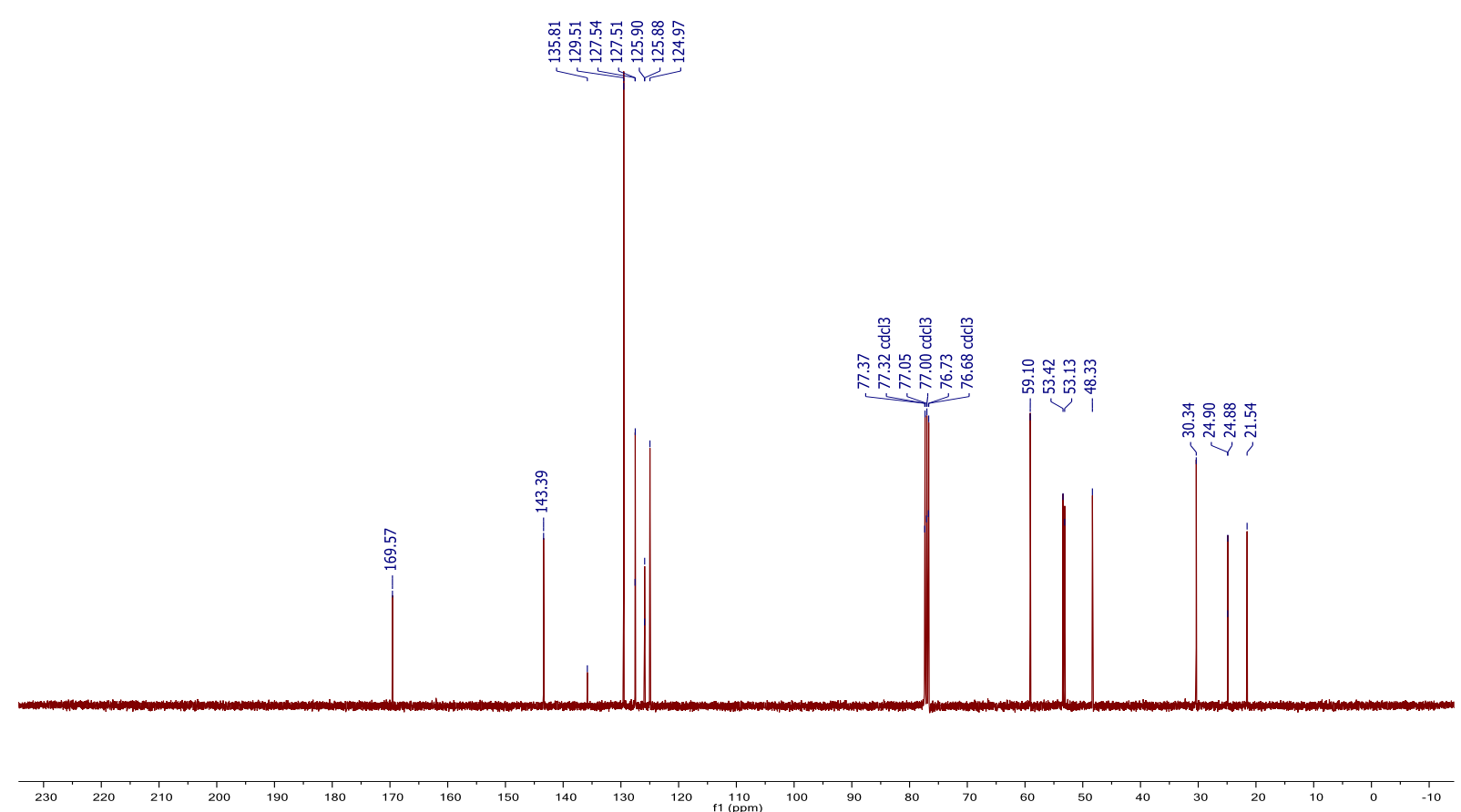

Figure S15. ${ }^{13} \mathrm{C}$ NMR of 1-(tosylpropyl)-2,5-dihydro-1H-pyrrole (10). 


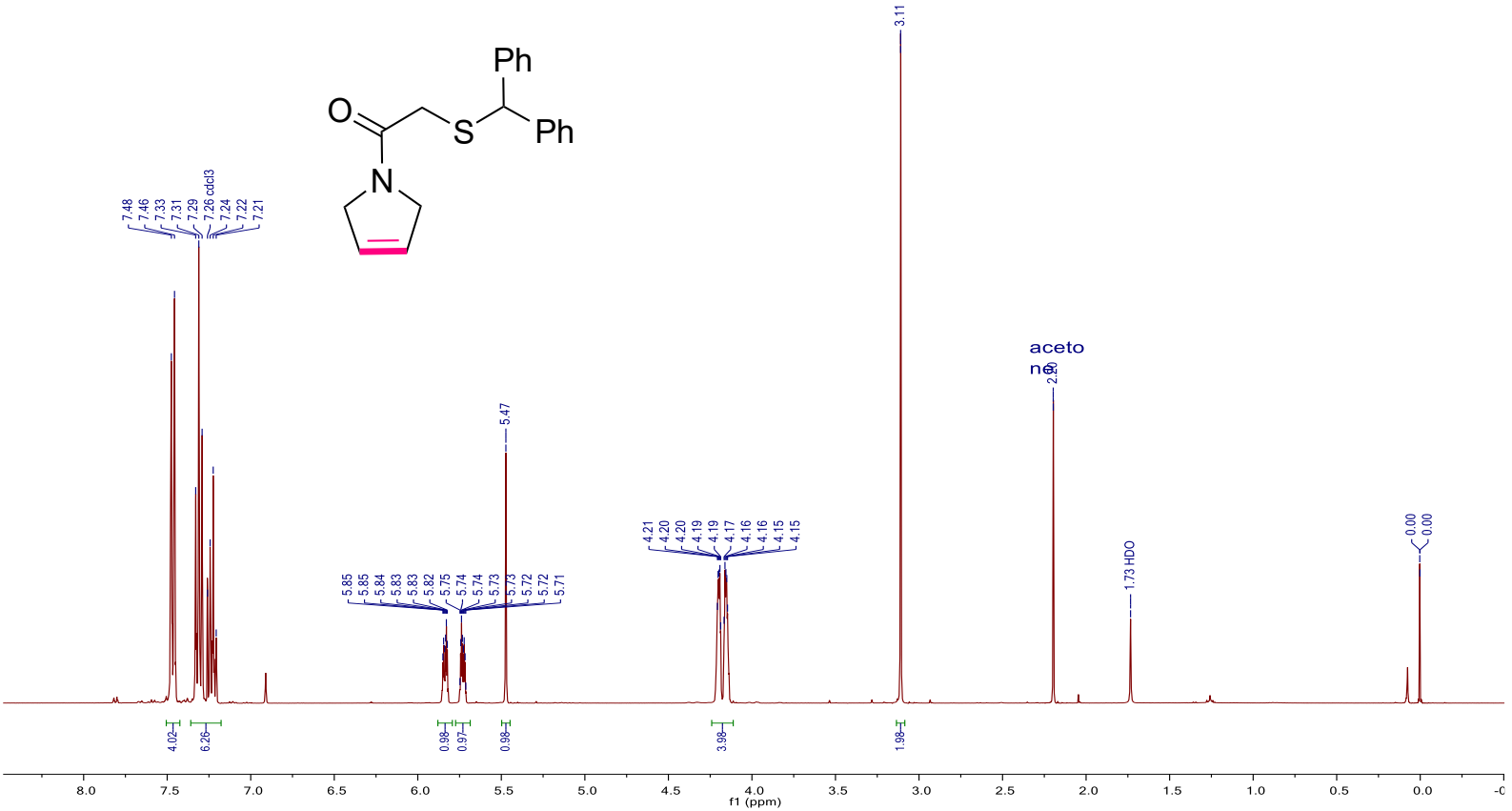

Figure S16. ${ }^{1} \mathrm{H}$ NMR of 2-(benzhydrylthio)-1-(2,5-dihydro-1H-pyrrol-1-yl)ethan-1-one (12).

MPA_CMOD_20180714_01/CARBON_01.fid/fid Solvent: cdcl3, Scans: 256, Relaxation: 3.0000

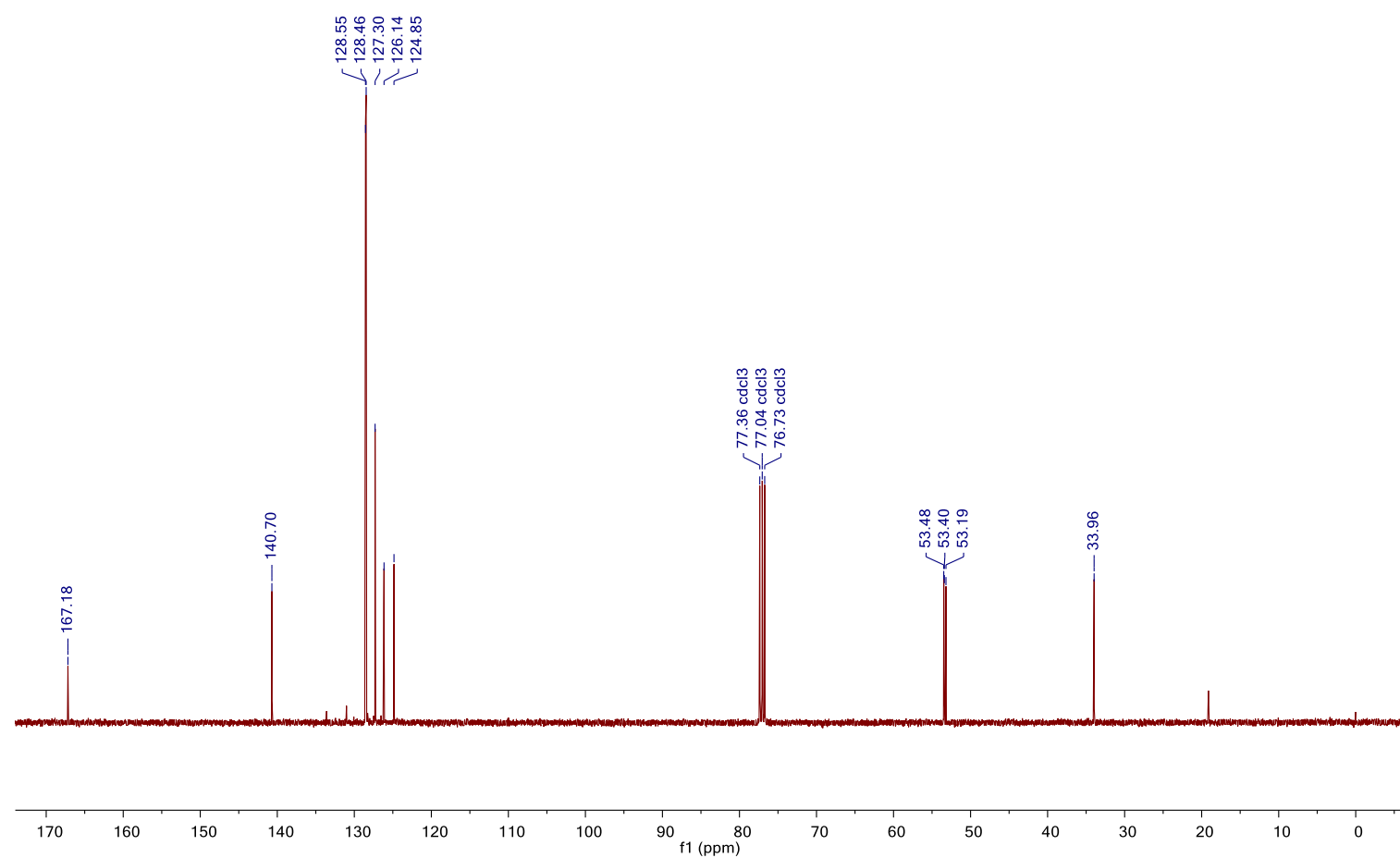

Figure S17. ${ }^{13} \mathrm{C}$ NMR of 2-(benzhydrylthio)-1-(2,5-dihydro-1H-pyrrol-1-yl)ethan-1-one (12). 


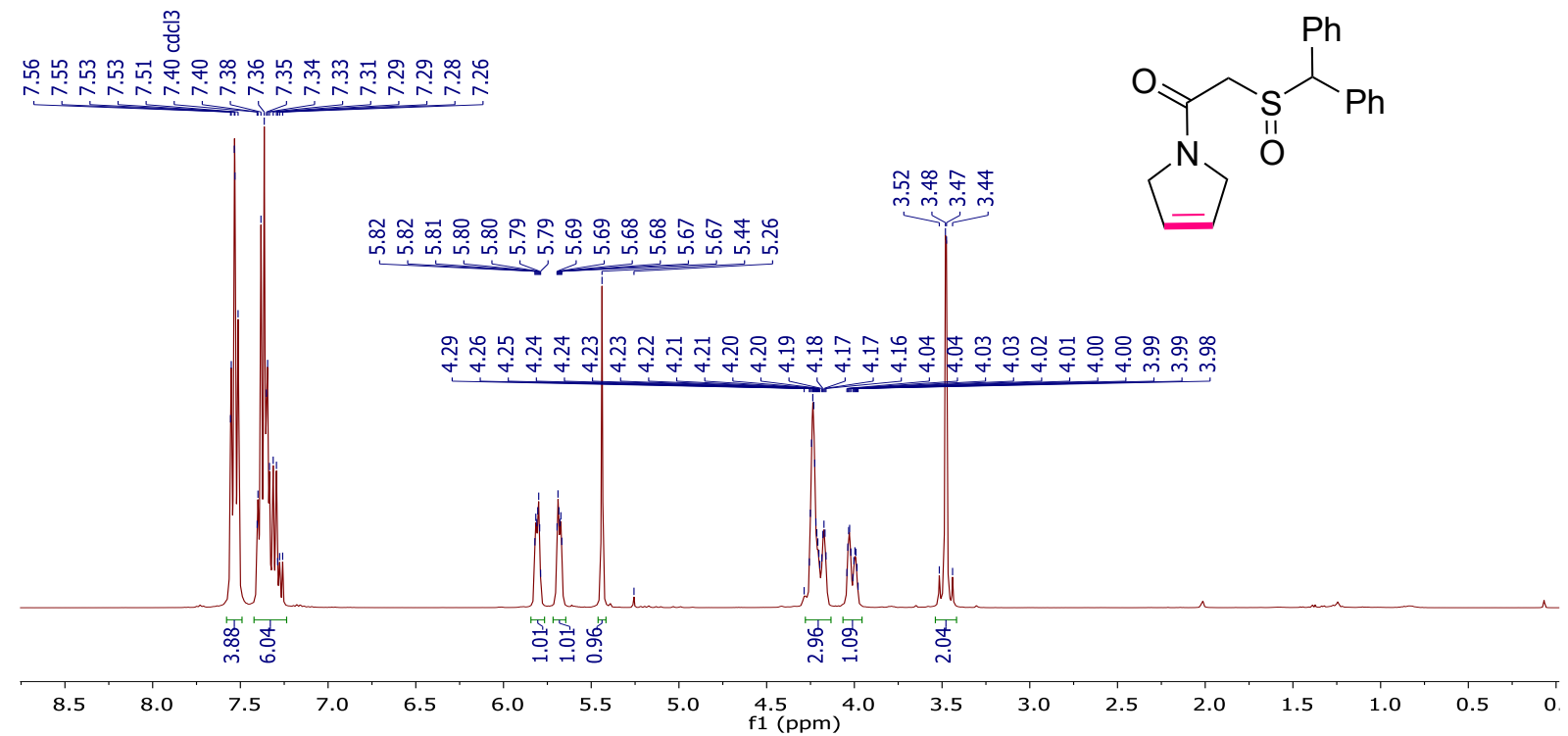

Figure S18. ${ }^{1} \mathrm{H}$ NMR of 2-(benzhydrylsulfinyl)-1-(2,5-dihydro-1H-pyrrol-1-yl)ethan-1-one (14).

MPA_COMOD_20191023_01/CARBON_01.fid/fid

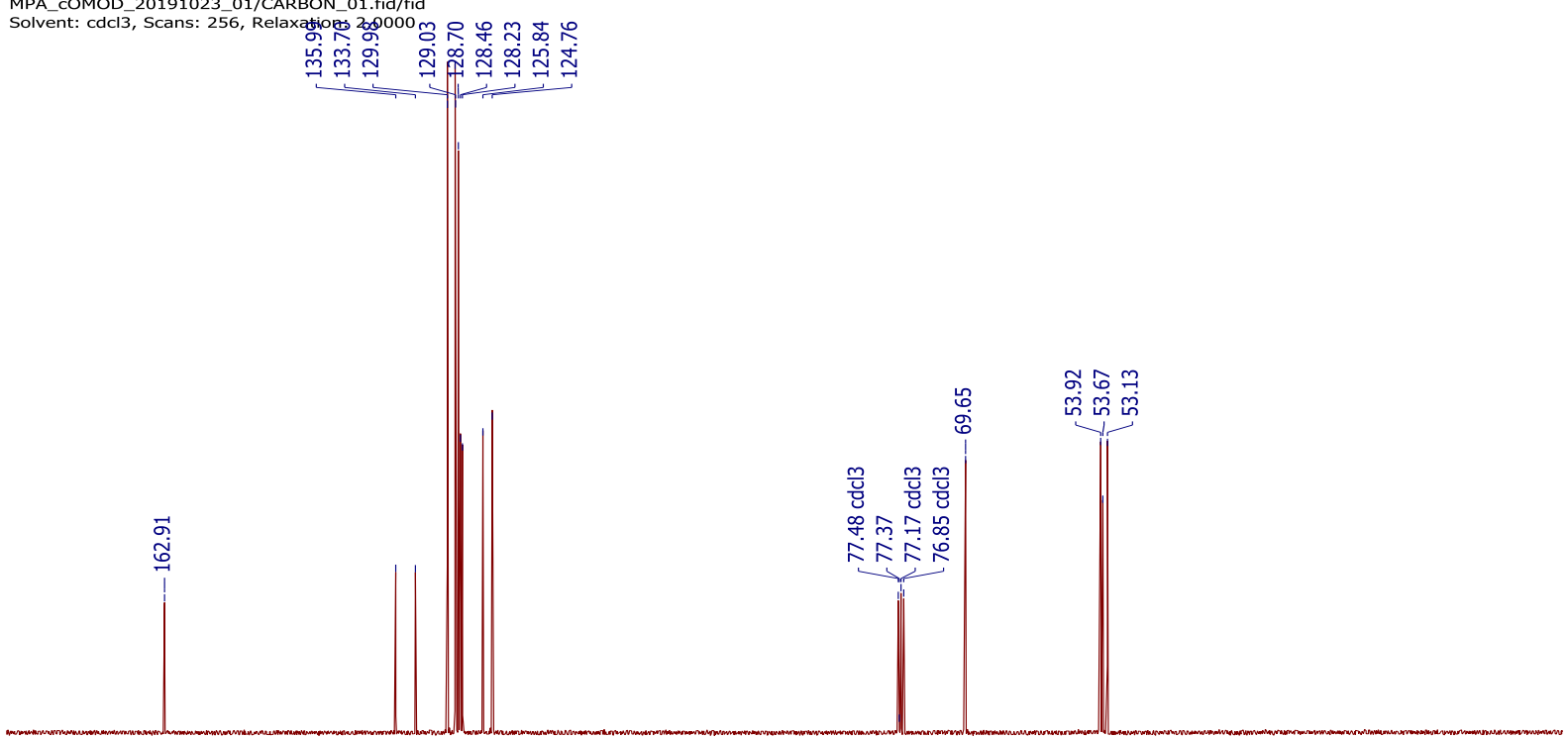

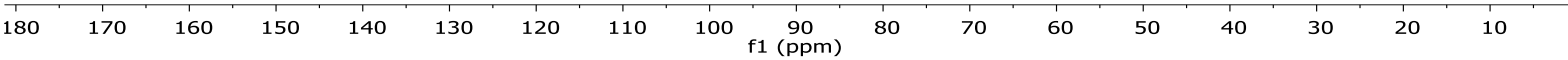

Figure S19. ${ }^{13} \mathrm{C}$ NMR of 2-(benzhydrylsulfinyl)-1-(2,5-dihydro-1H-pyrrol-1-yl)ethan-1-one (14). 
<smiles>CCCc1nn(C)c2c(=O)[nH]c(-c3cc(S(=O)(=O)N4CC=CC4)ccc3OCC)nc12</smiles>

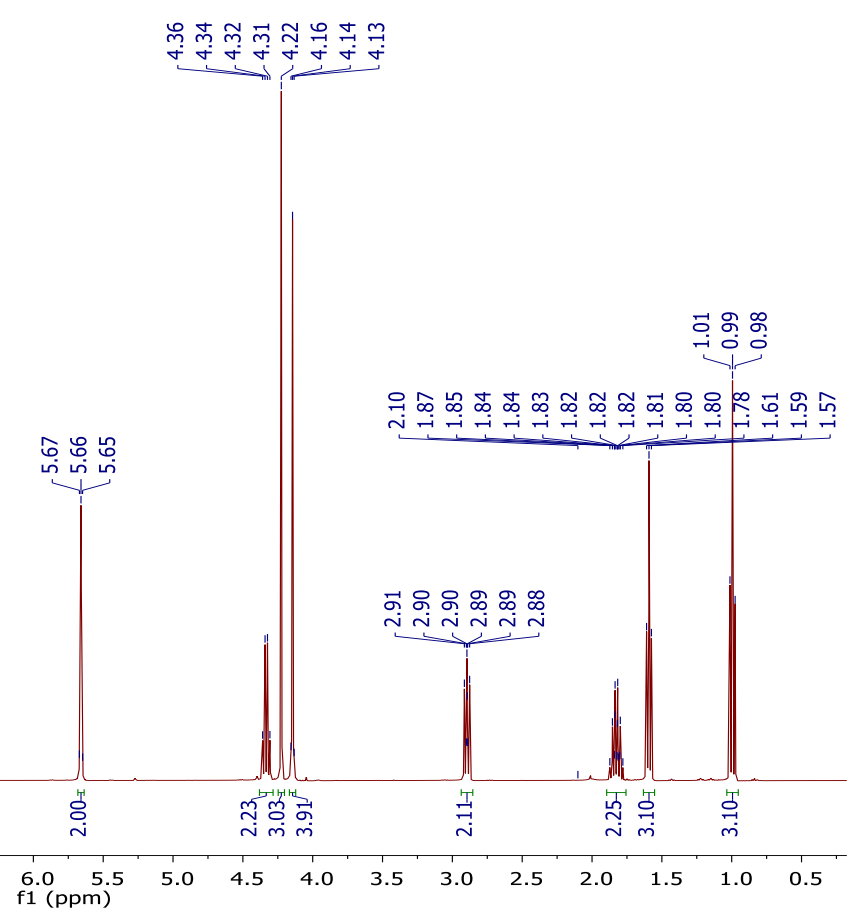

Figure S20. ${ }^{1} \mathrm{H}$ NMR of 5-(5-((2,5-dihydro-1H-pyrrol-1-yl)sulfonyl)-2-ethoxyphenyl)-1-methyl-3propyl-1,6-dihydro-7H-pyrazolo[4,3-d]pyrimidin-7-one (16).

MPA_cSil_20191023_01/CARBON_01.fid/fid
Solvent: cdcl3, Scans: 256, Relaxation: 2.000

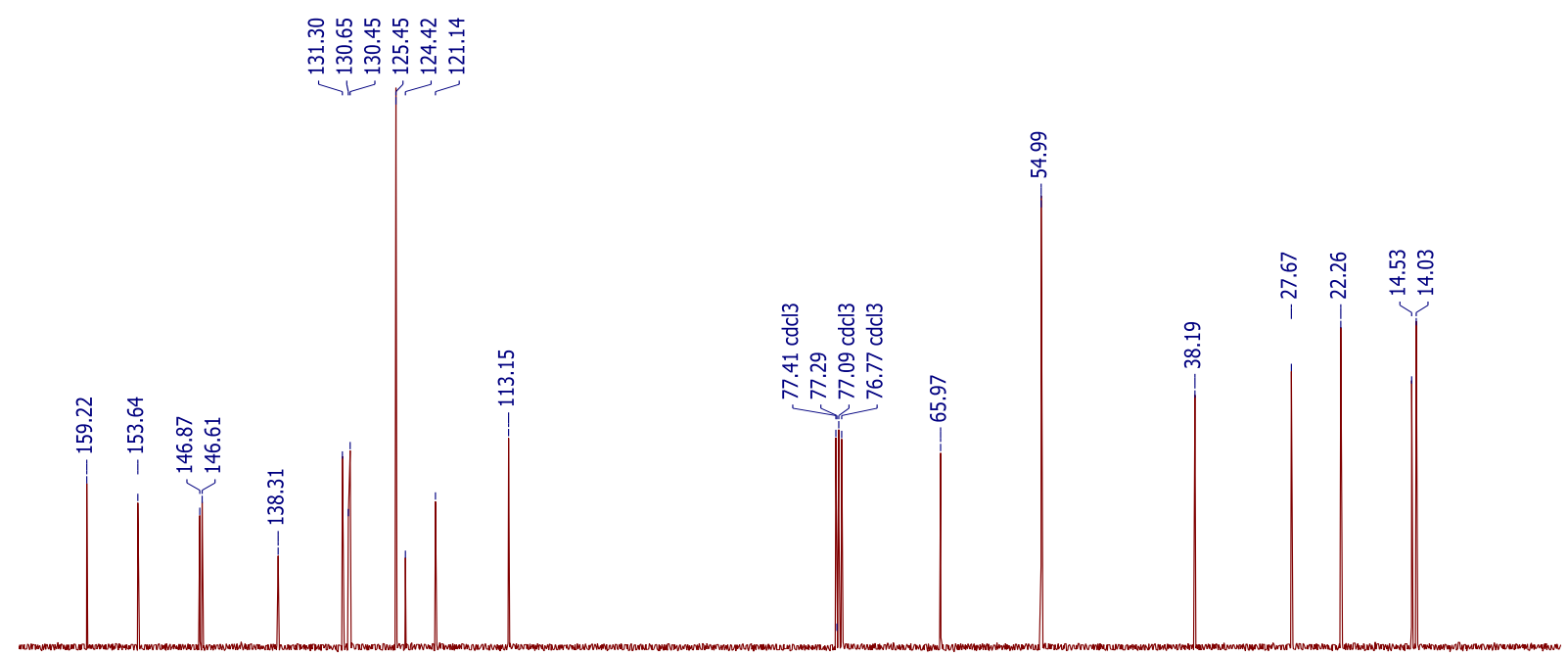

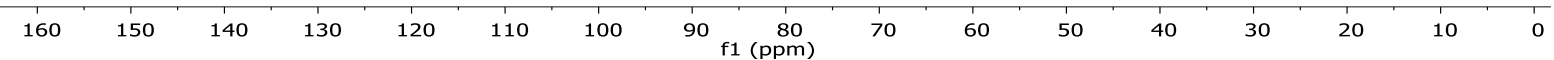

Figure S21. ${ }^{13} \mathrm{C}$ NMR of 5-(5-((2,5-dihydro-1H-pyrrol-1-yl)sulfonyl)-2-ethoxyphenyl)-1-methyl-3propyl-1,6-dihydro-7H-pyrazolo[4,3-d]pyrimidin-7-one(16). 


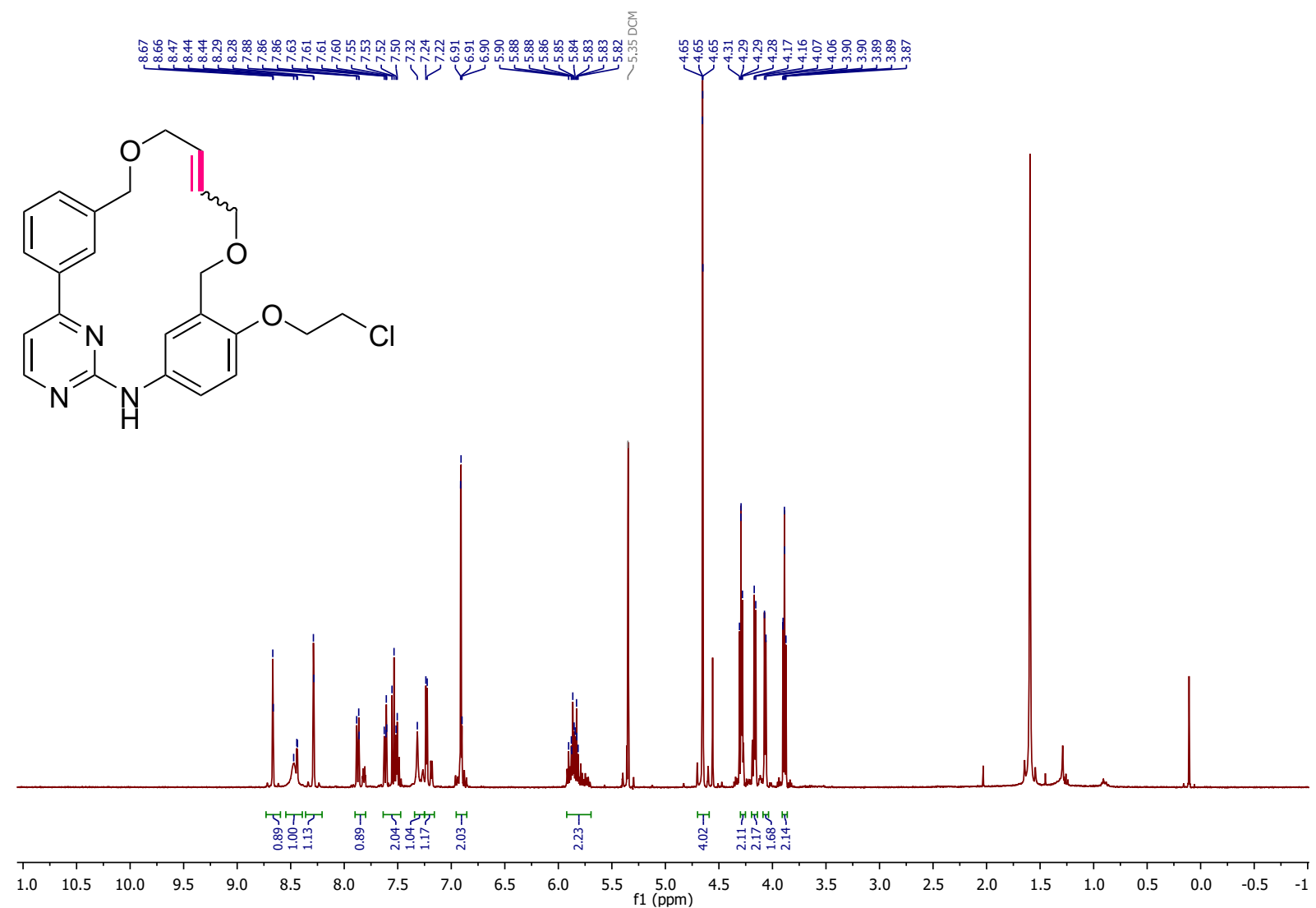

Figure S22. ${ }^{1} \mathrm{H}$ NMR of 44-(2-chloroethoxy)-6,11-dioxa-3-aza-2(4,2)-pyrimidina-1,4(1,3)dibenzenacyclododecaphan-8-ene (18).
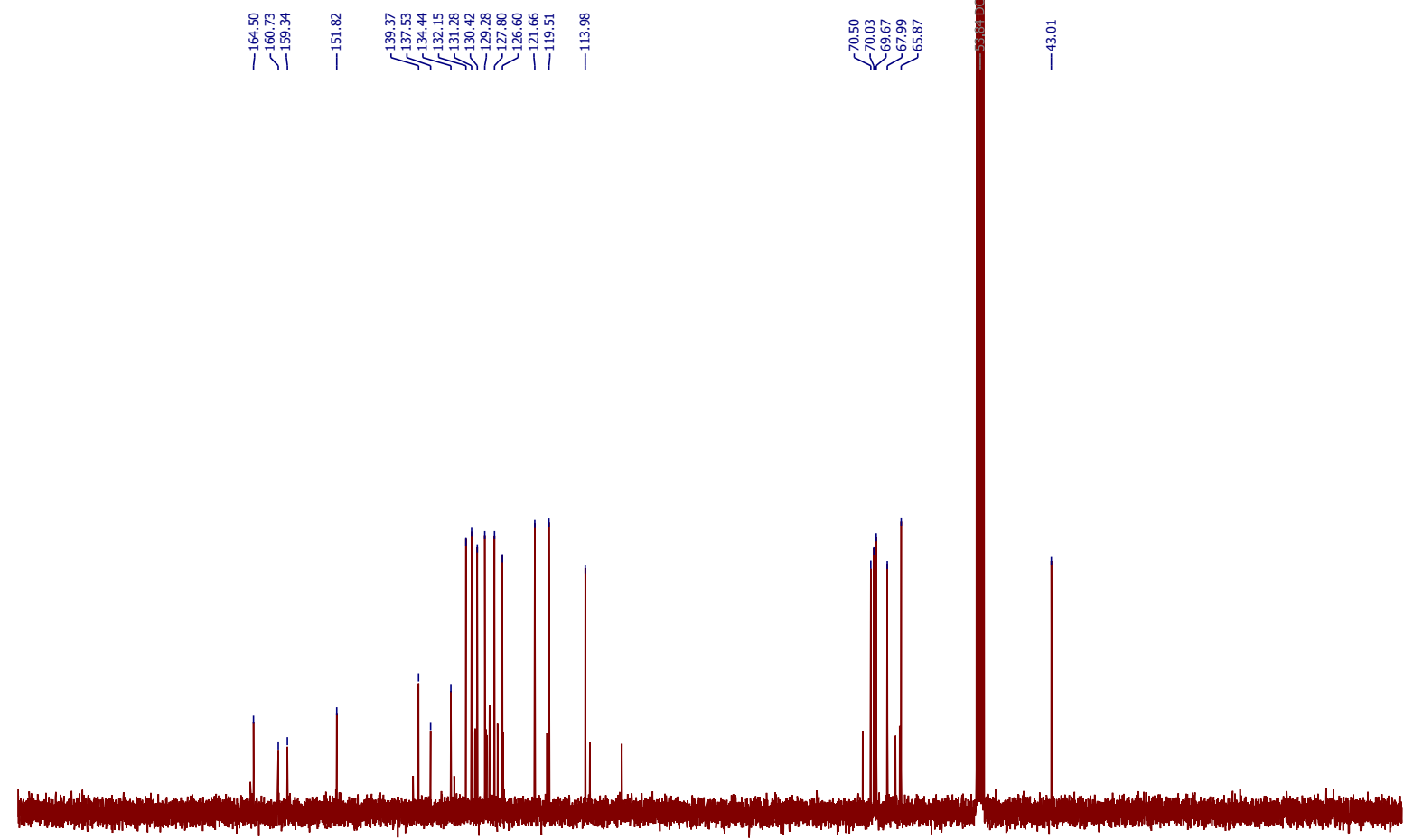

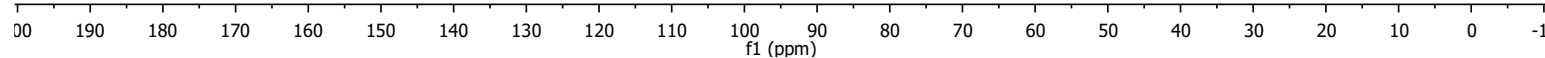

Figure S23. ${ }^{13} \mathrm{C}$ NMR of 44-(2-chloroethoxy)-6,11-dioxa-3-aza-2(4,2)-pyrimidina-1,4(1,3)dibenzenacyclododecaphan-8-ene (18). 


\section{References}

1. Taber, D. F.; Frankowski, K. J., Grubbs' Catalyst in Paraffin: An Air-Stable Preparation for Alkene Metathesis. The Journal of Organic Chemistry 2003, 68 (15), 6047-6048. DOI: 10.1021/jo030005p.

2. Szczepaniak, G.; Nogaś, W.; Piątkowski, J.; Ruszczyńska, A.; Bulska, E.; Grela, K., Semiheterogeneous Purification Protocol for the Removal of Ruthenium Impurities from Olefin Metathesis Reaction Products Using an Isocyanide Scavenger. Organic Process Research \& Development 2019, 23 (5), 836-844. DOI: 10.1021/acs.oprd.8b00392.

3. Rodriguez, S.; Uria, U.; Reyes, E.; Carrillo, L.; Tejero, T.; Merino, P.; Vicario, J. L., Enantioselective Synthesis of Tropanes: Brønsted Acid Catalyzed Pseudotransannular Desymmetrization. Angewandte Chemie International Edition 2020, 59 (17), 6780-6784. DOI: 10.1002/anie.202000650.

4. Chołuj, A.; Krzesiński, P.; Ruszczyńska, A.; Bulska, E.; Kajetanowicz, A.; Grela, K., Noncovalent Immobilization of Cationic Ruthenium Complex in a Metal-Organic Framework by Ion Exchange Leading to a Heterogeneous Olefin Metathesis Catalyst for Use in Green Solvents. Organometallics 2019, 38 (18), 3397-3405. DOI: 10.1021/acs.organomet.9b00287.

5. Małecki, P.; Gajda, K.; Gajda, R.; Woźniak, K.; Trzaskowski, B.; Kajetanowicz, A.; Grela, K., Specialized Ruthenium Olefin Metathesis Catalysts Bearing Bulky Unsymmetrical NHC Ligands: Computations, Synthesis, and Application. ACS Catalysis 2019, 9 (1), 587-598. DOI: 10.1021/acscatal.8b04783.

6. Zukowska, K.; Pączek, Ł.; Grela, K., Sulfoxide-Chelated Ruthenium Benzylidene Catalyst: a Synthetic Study on the Utility of Olefin Metathesis. ChemCatChem 2016, 8 (17), 2817-2823. DOI: $10.1002 /$ cctc.201600538.

7. Nienałtowski, T.; Krzesiński, P.; Baumert, M. E.; Skoczeń, A.; Suska-Kauf, E.; Pawłowska, J.; Kajetanowicz, A.; Grela, K., 4-Methyltetrahydropyran as a Convenient Alternative Solvent for Olefin Metathesis Reaction: Model Studies and Medicinal Chemistry Applications. ACS Sustainable Chemistry \& Engineering 2020, 8 (49), 18215-18223. DOI: 10.1021/acssuschemeng.0c06668.

8. William, A. D.; Lee, A. C. H.; Blanchard, S.; Poulsen, A.; Teo, E. L.; Nagaraj, H.; Tan, E.; Chen, D.; Williams, M.; Sun, E. T.; Goh, K. C.; Ong, W. C.; Goh, S. K.; Hart, S.; Jayaraman, R.; Pasha, M. K.; Ethirajulu, K.; Wood, J. M.; Dymock, B. W., Discovery of the Macrocycle 11-(2-Pyrrolidin-1-yl-ethoxy)14,19-dioxa-5,7,26-triaza-tetracyclo[19.3.1.1(2,6).1(8,12)] heptacosa-1(25),2(26),3,5,8,10,12(27),16,21,23decaene (SB1518), a Potent Janus Kinase 2/Fms-Like Tyrosine Kinase-3 (JAK2/FLT3) Inhibitor for the Treatment of Myelofibrosis and Lymphoma. Journal of Medicinal Chemistry 2011, 54 (13), 4638-4658. DOI: 10.1021/jm200326p. 